\title{
Roles of TRPA1 in Pain Pathophysiology and Implications for the Development of a New Class of Analgesic Drugs
}

\author{
Olivier Radresa ${ }^{\mathrm{a}}$, Henrik Dahllöf ${ }^{\mathrm{b}}$, Eva Nyman ${ }^{\mathrm{b}}$, Andreas Nolting ${ }^{\mathrm{b}}$, Jeffrey S. Albert ${ }^{\mathrm{a}}$ and \\ Patrick Raboisson*, \\ ${ }^{a}$ AstraZeneca R\&D Montreal, St-Laurent, H4S 1Z9, Canada; ${ }^{b}$ AstraZeneca R\&D Södertälje, Södertälje SE-151 85 , \\ Sweden
}

\begin{abstract}
The Transient Receptor Potential A1 (TRPA1) ion channel has evolved in animals to respond to signals from a variety of sensory stimuli. Many structural determinants of its multimodal activation have been identified to date. TRPA1 activities include responses to exogenous chemical irritants, responses to endogenous inflammatory mediators, zinc, voltage, temperature or stretch and subtle yet critical modulation by calcium ions. TRPA1 has emerged as an important target for several types of pain and inflammatory conditions because of its limited expression profile and its demonstrated roles in mediating different types of pain and sensitization of peripheral sensory afferents. Despite observed species differences in channel pharmacology, recent genetic evidence in human brings some hope that preclinical efficacy in disease models will translate to patient condition. During the past decade, various groups have investigated the development of a new class of analgesic drugs or anti-tussive agents aimed at blocking TRPA1 activity in primary sensory afferents. Several companies are advancing toward clinical proof of concept studies. This review aims to summarize key advances in the understanding of TRPA1 with regard to its roles and implications for patient conditions.
\end{abstract}

Keywords: TRPA1, TRP, AITC, cinnamaldehyde, drug discovery, analgesic, pain, asthma, COPD.

\section{INTRODUCTION: A SHORT HISTORY OF TRPA1 DISCOVERY}

The discovery of the Transient Receptor Potential Ankyrin 1 (TRPA1) protein and its characterization parallel that for the Transient Receptor Potential Vanilloid 1 (TRPV1) protein. Reports of the pro-inflammatory and noxious properties of their ligands preceded the discovery of the protein targets and of their mechanistic roles in pain signaling [1]. In 1986, almost 20 years before it was identified as a primary TRPA1 activator, mustard oil application was shown to cause cutaneous vasodilation and inflammatory responses, comparable to those triggered by antidromic nerve stimulation $[2,3]$. Mustard oil also induces nociceptor sensitization to mechanical and thermal stimuli [4]. TRPA1 cDNA, originally named ANKTM1 for Ankyrin-like with Transmembrane domains protein 1, was identified and cloned in 1999 from cultured human fibroblasts and included in the Transient Receptor Potential (TRP) channels family based on sequence identity [5]. Its primary structure exhibited some typical channel-like features including six transmembrane segments (TM) and an unusually high number $(>14)$ of ankyrin-repeats in its N-terminal part. The channels typically have low-selectivity for calcium and show multimodal activation [6]. The TRP channels family was originally divided into five subfamilies by Montell [7], it further extended to include seven subfamilies [8-10]. These seven groups are as

\footnotetext{
*Address correspondence to this author at Galderma R\&D, 2400 route des Colles - Les Templiers, 06410 Biot, France; Tel: +33(0)492954762;

Fax: +33(0)493957071; E-mail: patrick.raboisson.1@gmail.com
}

follow: TRPC (TRP Canonical), TRPV (TRP Vanilloid), TRPM (TRP Melastatin), TRPA (TRP Ankyrin), TRPN (TRP Non-mechanoreceptor C; which has not been found in mammals), the less closely related TRPP (TRP Polycystin; associated with polycystic kidney disease) and TRPML (TRP MucoLipin; associated with mucolipidosis type IV). TRPA1 is the only member of the TRPA group. In 2003, TRPA1 expression was detected among a variety of tissues and shown to be present in a subpopulation of mice nociceptive sensory neurons that also expressed TRPV1 (see below). A potential role in mechanotransduction was inferred in 2004 from TRPA1 expression profile and was implicated in hair-cell mechanotransduction in mice [11]. In nonmammals like the zebrafish, drosophila or nematode ( $\mathrm{C}$ elegans), a similar role was proposed for TRPN1 orthologs that also contained an unusually high number (29) of ankyrin repeats. The associated phenotypes of TRPN deficient animals were of developmental deafness or imbalance [12-15]. In mammals where TRPN genes are absent, it was initially thought that TRPA1 would take over TRPN function and mediate signal transduction for audition and balance [11, 16]. Despite localized TRPA1 expression and activity profile in cultured hair-cells, it appeared later that the auditory function in TRPA1-knockout mice was fully normal and no different than that of the wild-type $[17,18]$. Instead, TRPA1 knockouts exhibited reduced peripheral sensitization following mechanical stimulation in nociceptors (C-fibers, A-delta) and A-beta sensory neurons [19]. The early description of mustard oil causing pain sensitization upon crude application to the skin could then begin to be reconciled with a mecha- 


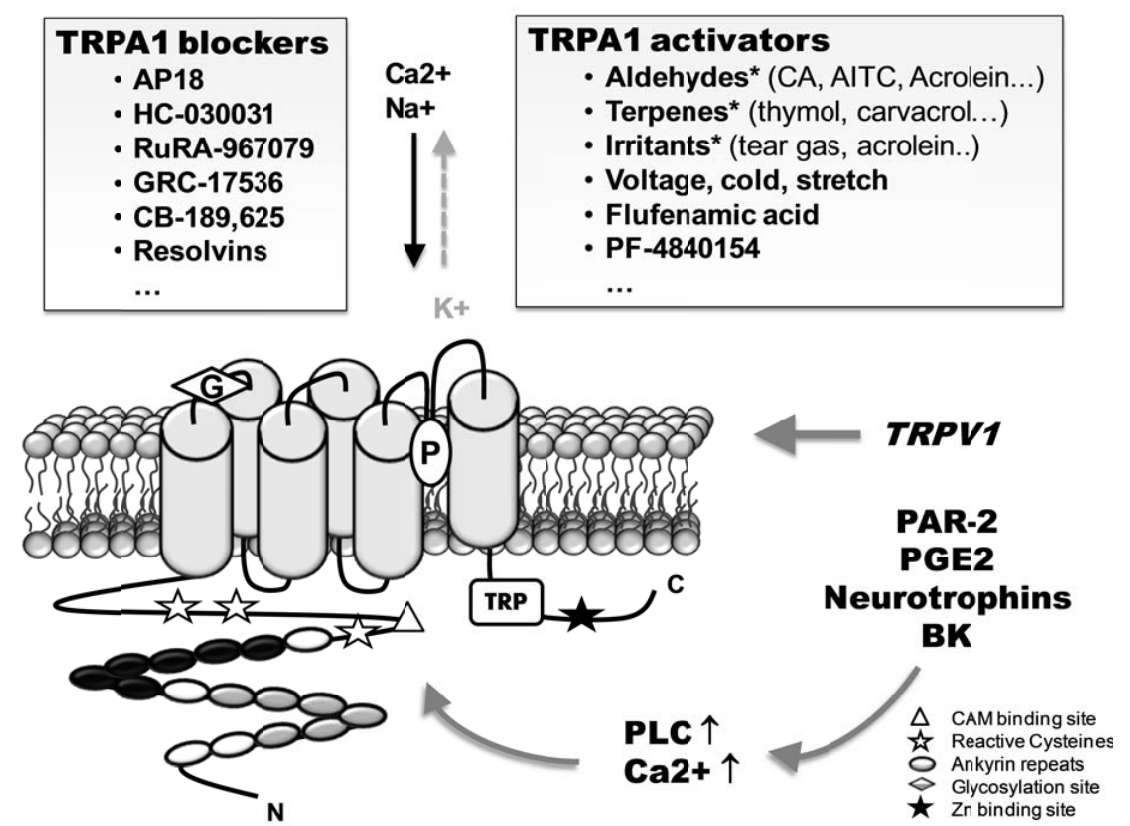

Fig. (1). "TRPA1 scheme and major modulators" The 16 ankyrin binding domains are depicted as two stretches of black (regulatory) and grey (enhancer) modules. The Zn-binding domain in the C-term part is indicated by a filled star. TRP = TRP box motif. Calmodulin, major reactive cysteines, glycosylation site and pore loop (P) are referred to by their respective symbols (see insert). Indirect modulation by GPCRs or neurotrophin receptors signaling pathways and interaction with TRPV1 are also indicated to illustrate TRPA1 role as polymodal integrator in neuron sensitization.

nistic role of TRPA1 in pain sensitization. This review is an attempt to summarize the current evidence supporting a role for TRPA1 in the pathophysiology of pain, from the bench to the bedside.

\section{TRPA1: Gene, Primary Structure and Protein Domains}

The TRPA1 gene in mammals is made up of 27 exons totaling about $50 \mathrm{~kb}$ and is located on chromosome $8 \mathrm{q} 13$ [5]. Human TRPA1 consists of 1119 a.a. whereas mouse and rat orthologs comprise 1125 a.a. The typical tetrameric assembly of TRPs was confirmed in the recent electron microscopy $16 \AA$ resolution three-dimensional TRPA1 structure from mice [20]. Each monomer is made up of six-membrane spanning segments (TM1-TM6) forming a functional channel by the assembly of a typical pore loop between TM5 and TM6 that forms the channel cation pore Fig. (1). Two potential sites for N-linked glycosylation are found in the extracellular loops (TM1-TM2) and both $\mathrm{C}$ - and $\mathrm{N}$ terminals are located on the intracellular side of the membrane. A special feature of TRPA1 is the long N-terminal domain with at least 14 ankyrin repeats (AR) An AR is a 33 amino-acid long motif containing two alpha-helices that appears as tandem arrangements in bacterial and eukaryotic proteins. The ARD forms a super helical spiral structure that may play a role in protein-protein interactions and also mechanotransduction $[21,22]$. A potential role of ARD in TRPA1 translocation and functional surface expression was inferred from impaired truncated mutants [23].

Distinct stretches of the ARD were shown to be involved in regulation of heat sensitivity and activation by covalent ligands and intracellular $\mathrm{Ca}^{++}$[24]. A distinct regulatory site has recently been identified and characterized in the distal cytosolic C-terminal end of human TRPA1 where a cluster of acidic residues (E1077 and D1080-D1082) affected the voltage-dependency of TRPA1 and its potentiation by $\mathrm{Ca}^{++}$ or chemical irritants (see below). Truncation of the 20 last Cterminal a.a. decreased $\mathrm{Ca}^{++}$-induced inactivation by threefold [25]. A different stretch of basic residues in the $\mathrm{C}$ terminal region proved critical for voltage activation when mutated (L969, K975, L988 and L989, L1092 and L1099) [26]. The cytosolic C-terminal end of TRPA1 seemed thus to play an essential role for the voltage activation of the channel.

Little is known about cellular trafficking of TRPA1; however, it has been demonstrated that direct in vitro application of protein kinase A (PKA) activators, phospholipase C (PLC) or TRPA1 agonist like allyl-isothiocyanate (AITC), the active component in mustard oil, led to increased immunodetection at the surface of recombinant cells. This process was partly dependent on SNARE-mediated vesicle fusion [27]. The same stimuli, applied in vivo, led to sensitization of the nocifensive response.

\section{TRPA1 can form Heterotetramers with TRPV1 in vitro}

In vitro TRPA1 subunits can form functional heteromeric complexes with TRPV1. The TRPA1/TRPV1 heteromers exhibit altered pharmacology and channel kinetics compared to either of the homomeric TRPA1 or homomeric TRPV1 [28-31]. In recombinant cells like CHO, TRPA1-TRPV1 complexes form on the cell surface; therefore, such complexes may serve as potential models to compare the pharmacology of the various TRPs oligomers in a recombinant system [32]. It has been suggested that a TRPV1 interaction plays a role as a regulator of AITC-induced desensitization of TRPA1 (see below), both in recombinant cells and sensory neurons, and that AITC-induced internalization of TRPA1 could be prevented by TRPV1 co-expression [33]. Heterotetramers pharmacology and sensitivity to multimodal 
activators are of potential physiological relevance for the peripheral sensory system as TRPA1 and TRPV1 mRNAs co-express in sub-populations of rat dorsal root ganglia and trigeminal ganglia neurons although it is unknown whether TRPA1-TRPV1 heteromers form in native tissues [34, 35].

\section{Cross-species Differences and Relevance to TRPA1 Drug Discovery}

The sequence identity between human- and rat-, mouseor dog proteins are only about $80 \%$ and discrete crossspecies variations may explain some key pharmacological and functional differences among TRPA1 orthologs. It is well documented that some compounds identified as antagonists at the human isoform show very different pharmacology at the rat receptor; this highlights the critical importance of surrogate model species in assessing the in vivo pharmacology [36, 37]. Several electrophilic compounds blocking human TRPA1 receptor have been shown to either lack activity or even activate the rat receptor (AMG7160, AMG2504, AMG9090, AMG5445, CMP1, CMP2 and CMP3) [36, 38]. Analogous discrepancies have been seen for non-reactive ligands like caffeine and menthol [39, 40]. The in vitro pharmacology (potency and type of effect) of caffeine, menthol and CMP1 on TRPA1 were similar between rhesus monkey and human channels (sharing 96.9\% a.a. identity) but neatly distinct between human and rat or mouse channels (nonetheless sharing $96.6 \%$ a.a. identity) indicating that, rather than rat or mice, rhesus monkey may be a good surrogate species to human in preclinical studies [41]. Residues in the distal N-terminus between amino acid 231 and 287 are critical to explain the shift of some ligands from antagonist to agonist. Mouse TRPA1 mutant M268P resembles the human ortholog and this single-point mutation was sufficient to shift caffeine activity from activator to inhibitor on the rodent channel. Yet, the corresponding reverse mutation in human TRPA1 (P267M) was not sufficient to trigger a shift in the opposite direction, suggesting that complex interactions between distinct parts of the channels e.g. TM5 and TM6 explain the specific pharmacology of orthologs and the activity of some ligands like menthol [38, 42, 43]. Within the same species, the pharmacological profile may also follow a bimodal trend of concentration dependence like in the case of menthol that was shown to activate mice TRPA1 at low concentrations and block it at higher ones [44].

The ARD is another region of importance for pharmacological species specificity, particularly for thermal and chemical opening modalities. Rattlesnake and drosophila TRPA1 orthologs are activated by heat and seem less sensitive to chemicals such as AITC than their human counterpart. Swapping the first 10 ankyrin repeats in the human isoform by those of the snake rendered the chimera heat sensitive while it retained its original human AITC sensitivity. Closer mutational analysis revealed that rattlesnake TRPA1 contained two functional AR regions (AR 3-8 and AR10$15)$; each of these was sufficient to confer heat sensitivity to the human orthologs, yet with different temperature thresholds of activation. The N-terminal ARD of TRPA1, by integrating thermosensation, ligand modulation and also calcium sensitivity (see below) seems thus to act as a molecular integrator of physiological signals in TRPA1 expressing neurons [24].
All these findings stress the need for caution when ligands developed against the human channel are evaluated in other species during preclinical development; careful assessment of the cross-species reactivity is warranted.

\section{BIOPHYSICAL PROPERTIES OF TRPA1}

\section{Electrophysiological Properties of TRPA1 Channels}

TRPA1 channels are characterized by a relatively high single channel conductance. Homomeric channels have a conductance of about 110-173 pS [16, 45-47]. Extracellular physiological $\mathrm{Ca}^{++}$and $\mathrm{Mg}^{++}$concentrations reduce the inward single channel conductance at negative potentials to about $65 \mathrm{pS}$. A gradual rundown of activity has been reported when the channel is recorded in cell-free membrane patches. This was seemingly caused by the absence of intracellular inorganic polyphosphates in excised patches; this changes the functional state of the channel making it insensitive to pungent chemicals and $\mathrm{Ca}^{++}$activation $[46,48]$. The biophysical properties of the pore have been explored by permeability studies with inorganic and organic cations. The monovalent cation permeability follows the sequence $\left(\mathrm{Rb}^{+}>\right.$ $\mathrm{K}^{+}>\mathrm{Cs}^{+}>\mathrm{Na}^{+}>\mathrm{Li}^{+}$) when constitutive TRPAl activity is recorded. When activated by AITC, the relative permeability of inorganic cations in excised patches has been determined as $\left(\mathrm{Ca}^{++}>\mathrm{Ba}^{++}>\mathrm{Mg}^{++}>\mathrm{NH}^{4+}>\mathrm{Li}^{+}>\mathrm{Na}^{+} \geq \mathrm{K}+\geq \mathrm{Rb}^{+}>\right.$ $\left.\mathrm{Cs}^{+}\right)[48]$.

As previously observed for TRPV1, activated TRPA1 undergoes agonist-dependent pore dilation from an original $11 \AA$ diameter to $14 \AA$ in its narrowest portion upon persistent stimulation by AITC [49]. TRPA1 pore dilation eventually allowed for permeation of large cationic molecules like Yo-Pro (376 Da; fluorescent probe), N-methyl-D-glucamine (195.2 Da) or the lidocaine derivative QX314 (363Da) [50] [51]. Probe permeation was reversed by TRPA1 antagonists like ruthenium red $(\mathrm{RuR})$ and $\mathrm{HC}-030031$ and, regardless of their reactive nature, pore dilation was observed both with electrophiles (AITC, cinnamaldehyde, 4-hydroxy nonenal) and non-electrophile compounds (farnesyl thiosalicylic acid and URB597). Both calcium and lasting agonist application dynamically and reversibly regulated pore dilation in TRPA1, similar to what was shown previously for TRPV1 $[52,53]$. As a correlate of pore dilation, a $30 \%$ increase in divalent cation selectivity $(\mathrm{PCa} / \mathrm{PNa})$ and an increase in fractional $\mathrm{Ca}^{++}$current were also observed [49]. Even modest changes in $\mathrm{Ca}^{++}$permeability occurring from dynamic pore dilation could play a role in TRPA1 (and TRPV1) regulations in nociceptive neurons to alter their excitability. Following stimulation with voltage ramps, TRPA1 showed marked outward rectification at positive membrane potentials, indicative of the voltage-dependency of the channel $[26,44]$. In absence of intracellular $\mathrm{Ca}^{++}$and in recombinant system, the outward current is measured above $+60 \mathrm{mV}$ while the voltage for half-maximal activation $\left(\mathrm{V}_{\text {half }}\right)$ corresponded to $+155 \mathrm{mV}$. Interestingly, this voltage dependence is strongly shifted leftward by increasing internal $\mathrm{Ca}^{++}$. For instance, at $6 \mu \mathrm{M}$ intracellular $\mathrm{Ca}^{++}$, TRPA1 $\mathrm{V}_{\text {half }}=14 \mathrm{mV}$ and is reduced to $-1 \mathrm{mV}$ at $100 \mu \mathrm{M}$ [54]. Physiological intracellular $\mathrm{Ca}^{++}$level $\left(\left[\mathrm{Ca}^{++}\right] \mathrm{i}\right)$ usually reaches $100 \mathrm{nM}$ in most DRG cells, but in medium-sized neurons (30 $\mu \mathrm{m}$ diameter), following NGF stimulation or in inflammatory conditions, the intracellular calcium concentration can reach 100 -fold 
higher concentrations, potentially making voltage a physiologically relevant regulator of TRPA1 also in the absence of macromolecular ligands $[55,56]$.

\section{Calcium Regulation of TRPA1 Activity}

Calcium ions seem to play a crucial and dual role in controlling the gating behavior of TRPA1, inducing activation or potentiation as well as inactivation. The molecular basis of $\mathrm{Ca}^{++}$gating is complex and involves several distinct structural domains of the protein. Several findings indicate that $\mathrm{Ca}^{++}$-mediated TRPA1 activation and potentiation are induced by the elevation in intracellular calcium level $\left[\mathrm{Ca}^{++}\right] \mathrm{i}$. At micromolar concentrations, $\left[\mathrm{Ca}^{++}\right] \mathrm{i}$ activates TRPA1 in a voltage-dependent way, slowing channel inactivation and causing persistent activation $[47,54]$. Similarly elevation of $\left[\mathrm{Ca}^{++}\right] \mathrm{i}$ by thapsigargin (a specific inhibitor of endoplasmic $\mathrm{Ca}^{++}$-ATPase) or by histamine (which signals to induce $\mathrm{Ca}^{++}$ mobilization from intracellular stores) were also shown to activate TRPA1 [57]. Direct $\mathrm{Ca}^{++}$binding to an EF-hand motif in the intracellular N-terminus seemed responsible for $\mathrm{Ca}^{++}$-induced activation $[47,54]$. However, ev-en in mutants that are deficient for this binding site, some remaining levels of calcium sensitivity remained $[23,57]$.

TRPA1 activation and potentiation would also require access for $\mathrm{Ca}^{++}$in the open channel. In $\mathrm{Ca}^{++}$-free solution, reactive agonists induced slow-activating, persistent TRPA1 current. TRPA1 pore mutant D918A, which has strongly reduced $\mathrm{Ca}^{++}$permeability, is also deficient for calciuminduced potentiation upon increasing extracellular calcium level $\left(\left[\mathrm{Ca}^{++}\right] \mathrm{o}\right)$. In the same mutant, $\mathrm{Ca}^{++}$sensitivity (activation and inactivation) was rescued by lowering the intracellular calcium chelator EGTA, suggesting that $\mathrm{Ca}^{++}$entry through the pore is leading to channel activation via accumulation of $\left[\mathrm{Ca}^{++}\right] \mathrm{i}[57]$. In contrary, high millimolar extracellular $\mathrm{Ca}^{++}$concentration $\left[\mathrm{Ca}^{++}\right]$o led to a fast-inactivating, transient TRPA1 current. Add-back of millimolar $\left[\mathrm{Ca}^{++}\right] \mathrm{o}$ to a $\mathrm{Ca}^{++}$-free solution led to a quick change towards fast potentiation and fast inactivation of agonist-induced currents [16, $47,57]$. As a result, signaling events increasing $\left[\mathrm{Ca}^{++}\right] \mathrm{i}$ have a strong potential to modulate TRPA1 responses. Inflammatory mediators signaling through an increase in phospholipases $\mathrm{C}$ (PLC) and an increase in cytosolic $\left[\mathrm{Ca}^{++}\right] \mathrm{i}$, or direct $\mathrm{Ca}^{++}$influx mediated by TRPV1 and other plasma membrane calcium channels are all additional means of modulating TRPA1 activity $[18,58,59]$. In this regard, TRPV1 was proposed to play a direct role in the regulation of TRPA1 activity, altering the open-probability, magnitude and voltage dependency of mustard oil induced TRPA1 currents [31, 60]. TRPA1 itself might regulate its own $\mathrm{Ca}^{++}$gating upon activation by endogenous agonists or environmental irritants, and therefore control nociceptive signaling via a $\mathrm{Ca}^{++}$dependent biphasic feedback loop [47].

\section{TRPA1 IS A POLYMODAL INTEGRATOR OF NOCI- CEPTIVE STIMULI}

\section{TRPA1 Expression Profile under Basal Conditions}

Unlike many other potential targets for analgesia, TRPA1 was originally shown to have a distinct and restricted distribution pattern in peripheral sites of importance for pain processing. Consistent with a role in nociception, TRPA1 is expressed in dorsal root ganglia (DRG) and trigeminal gan- glia (TG) neurons of sensory primary afferents [16, 31, 35, 61]. In situ hybridization studies in mice demonstrated TRPA 1 mRNA expression in a large number of smaller nociceptive cells (approximately $37 \%$ of all TG and $57 \%$ of all DRG neurons, respectively) [16]. Similar results have been obtained in intact rat lumbar DRG where approximately $40 \%$ of all L5-L6 DRG cells were positive for TRPA1 mRNA. Furthermore, the results indicated that these neurons did not express neurofilament 200, but peptidergic markers of nociceptive neurons such as calcitonin gene-related peptide (CGRP), TRPV1 and also the NGF receptor TrkA. Immunohistochemistry experiments confirmed TRPA1 protein expression in small peripherin-positive nociceptors [16, 35].

From the cell bodies TRPA1 is trafficked towards peripheral nerves and central terminals of the primary afferents. In rodents TRPA 1 is expressed by about $50 \%$ of small peptidergic C-fiber nociceptors [31, 61] although it has also been reported in non-peptidergic nociceptors that bind isolecitin IB4 [62]. In human, TRPA1 has been detected in the intact peripheral nervous system [63] as well as in lingual nerve neuromas [64].

TRPA1 is also present in non-somatosensory neurons, including vagal fibers [65] and sympathetic neurons [66] and in non-neuronal tissues such as urothelial cells $[67,68]$ and basal keratinocytes [63], hair cells in the inner ear [69] and native endothelial cells [70]. The expression and activity profile of TRPA1 in a number of neuronal and non-neuronal locations suggest a functional role of TRPA1 in many other physiological contexts than pain (see [71] for a recent review).

\section{Activation of TRPA1 by Exogenous Stimuli}

TRPA1 is gated by a wide range of environmental irritants, pungent natural compounds and riot control agents such as mustard oil (AITC), garlic (allicin), ginger, wintergreen and cinnamaldehyde (CA), nicotine and various tear gases, all of which can induce pain, nocifensive behaviors and/or sensory neurons sensitization in animals and man Fig. (2), Table 1 [4, 11, 58, 61, 72]. Many structurally unrelated TRPA1 activators are electrophilic in nature and typically activate the channel following covalent binding to specific residues [73]: CA, acrolein, AITC, iodoacetamide and most plant terpenes (e.g. thymol, carvacrol) belong to this category Fig. (1). Using a combination of cysteine scanning mutagenesis, $\mathrm{Ca}^{++}$ fluorescence assays and electrophysiology their mechanism of action was shown to occur through covalent binding at specific cysteine residues on the intracellular N-terminal part of the channel. In mice, three of the 31 cysteine residues, C415, C422 and C622 (corresponding to C414, C421 and C621 of the human isoforms), turned out to be essential for mediating this covalent channel activation Fig. (1) [73, 74]. In agreement, inert chemical analogs of CA or acrolein were inactive at TRPA1, indicating that thiol reactivity is essential within these specific structural scaffolds [74]. Icilin however, a naturally neutral activator seemed to exert its activity via a thiol-independent mechanismm. Depending on the TRPA1 conformation, C622 and C666 might take part in a dynamic network of disulfide bonds with spatially close cysteines residues, in addition to be interacting with reactive small molecule ligands [75]. Upon modeling of TRPA1 
Table 1. Properties of Representative TRPA1 Agonists ${ }^{\text {aAITC }}$

\begin{tabular}{|c|c|c|c|}
\hline Compd & Name or sponsor & EC $_{\mathbf{5 0}}$ & Ref. \\
\hline \hline $\mathbf{1}$ & AITC & h: $2-34 \mu \mathrm{M}$ & {$[4,99]$} \\
\hline $\mathbf{2}$ & Cinnamaldehyde & h: $13-125 \mu \mathrm{M}$ & {$[58,99]$} \\
\hline $\mathbf{3}$ & CN tear gas & h: $30 \mathrm{nM}$ & h: $0.9 \mathrm{nM}$ \\
\hline $\mathbf{4}$ & CS tear gas & h: $23 \mathrm{nM}, \mathrm{r}: 97 \mathrm{nM}$ & {$[87]$} \\
\hline $\mathbf{5}$ & PF-4840154 & h: $50 \mathrm{pM}$ & {$[184]$} \\
\hline $\mathbf{6}$ & J\&J & {$[201]$} & \\
\hline
\end{tabular}

${ }^{\mathrm{a}} \mathrm{h}=$ human; $\mathrm{r}=$ rat

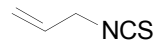

$1 ;$ AITC<smiles>O=C/C=C/c1ccccc1</smiles>

2; Cinnamaldehyde

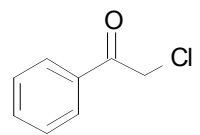

3; CN tear gas

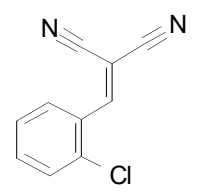

4; CS tear gas

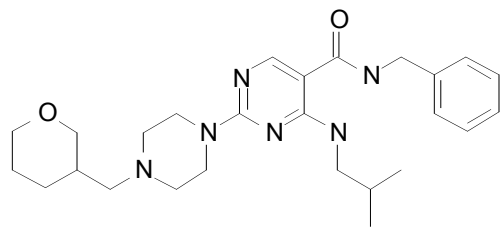

5; PF-4840154

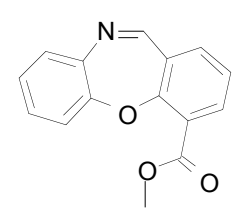

6; J\&J

Fig. (2). Structures of agonists shown in Table 1.

sequence in its low resolution electron density map, C622 and C666 seemed to sit in a cluster of reactive residues within a linker region between the ARD and the transmembrane portion of the channel. These observations suggest a model where structural crosstalk between these regions plays a role in channel activation and desensitization [20].

A preclinical animal model of particular interest to pain researchers is the formalin test [76], where a diluted formalin solution (usually $2 \%$, which corresponds to a $0.74 \%=$ $246 \mathrm{mM}$ formaldehyde solution) is injected into the hind paw of rodents to produce a standard biphasic pain response pattern. Formaldehyde has also reactive properties and has been suggested to trigger nocifensive behaviors through its capacity to bind and activate TRPA1. Using calcium imaging and electrophysiology in heterologous cells transfected with TRPA1, formaldehyde was shown to increase $\left[\mathrm{Ca}^{++}\right] \mathrm{i}$ with an estimated $\mathrm{EC}_{50}$ around $350 \mu \mathrm{M}$ [77], a concentration likely to be exceeded locally in the hind paw skin following injection of a $2 \%$ formalin solution ( $246 \mathrm{mM}$ formaldehyde). Interestingly, nociceptive behaviors during both phases of the formalin test are strongly reduced in TRPA1 knockout mice or by pharmacological blockade of TRPA1 [78].

In addition to formalin, AITC and $\mathrm{Ca}^{++}$are the most characterized and frequently used TRPA1 agonists in experimental pain models. AITC activates C-mechano-heat nociceptors (CMHs) leading to neuropeptide release, causing vasodilation, hyperalgesia and pain $[4,66]$. Therefore AITC (mustard oil) has been used in experimental preclinical and clinical pain studies for many years [79-82]. Its application to the human skin elicits a sharp and burning pain sensation, followed by development of sensitization, which is characterized by hyperalgesia (increased pain sensation to a normally painful stimulus) and allodynia (pain elicited by a nonpainful stimulus) [81]. Using various in vitro protocols, AITC activates human and rat TRPA1 at low micromolar concentrations $\left(\mathrm{EC}_{50}=1.9-33.5 \mu \mathrm{M}\right)$ (Table 1, cinnamaldehyde Fig. (2) [83]. Specificity of AITC for TRPA1 has been demonstrated in vivo using genetic deletion of TRPA1 in mice, where AITC-induced pain response and inflammation were lost $[17,18]$. In vitro, AITC activates TRPV1, although at much higher concentration $\left(\mathrm{EC}_{50}=1.8 \mathrm{mM}\right)$ [84]. $\mathrm{CA}$ is well known for its use in food and as a fragrance additive and therefore its physiological effects are well documented. In vitro reports have shown that $\mathrm{CA}$ activates TRPA1 in the micromolar range $\left(\mathrm{EC}_{50}=6.5-19 \mu \mathrm{M}\right)$ [83]. In healthy volunteers, topical application of $0.2-10 \%(1.5-75 \mathrm{mM}) \mathrm{CA}$ solution to the forearm caused spontaneous burning pain, hyperalgesia, and neurogenic inflammation [85]. The exact concentration of CA in the dermis following such an application is not known, but it cannot be excluded that it reached a level at which CA activates other thermo-TRPs, in addition to TRPA1. Indeed, in recombinant systems $\mathrm{CA}$ is reported to block TRPM8 at millimolar concentrations $\left(\mathrm{EC}_{50}=1.5 \mathrm{mM}\right)$ and to activate TRPV3 in the same range [86]. 
o-Clorobenzylidene malononitrile (CS) has been used as a tear gas by military and police forces worldwide for decades. Agents such as CS are electrophilic chemicals; their incapacitating effects result from instant pain and irritation of the eyes, excessive tearing and cramp of the eyelids (blepharospasm). Recently TRPA1 was established as the molecular target for CS. CS was shown to be a selective and potent agonist of human TRPA1 with an $\mathrm{EC}_{50}$ of $0.9 \mathrm{nM}$ (calcium fluorescence) $[87,88]$. Similar values where obtained for the rat isoform $\left(\mathrm{EC}_{50}=0.7\right.$ and $0.2 \mathrm{nM}$ at the human and rat TRPA1, respectively; (E. Nyman, AstraZeneca R\&D: unpublished data). Pain responses to CS have been assessed in humans following application on the tongue and cornea in healthy volunteers [89]. The sensory detection threshold after ocular administration was $730 \mathrm{nM}$ with an $\mathrm{EC}_{50}$ of $3.2 \mu \mathrm{M}$ for blepharospasm. Administration on the tongue yielded an $\mathrm{EC}_{50}$ of $6.8 \mu \mathrm{M}$ for a painful stinging and burning sensation. In rats, intradermal injection of CS $(5 \mu \mathrm{L}$, $160 \mathrm{nM}-16 \mathrm{mM}$ ) produced a dose-dependent increase in nocifensive behaviors (lifting, shaking, biting and licking of the injected paw) as well as heat hyperalgesia and mechanical allodynia (G. Martino, AstraZeneca R\&D, unpublished data).

\section{The Question of TRPA1 as Transducer of Noxious Cold}

TRPA1 involvement in the cold sensitivity of sensory neurons is still debated $[4,31,58,90]$.

Experiments using patch clamp and calcium fluorimetry in recombinant systems provided the first evidence that TRPA1 was a sensor of noxious cold. In recombinant systems, the activity of TRPA1 was markedly enhanced at temperatures below $17{ }^{\circ} \mathrm{C}$ or in the presence of Icilin [31], indicating that sensation of cold temperatures or their perception elicited by chemicals are mediated via TRPA1.

In contrast, data from different groups studying the role of TRPA1 as a noxious cold sensor in native systems of cultured sensory neurons failed to link the function of TRPA1 to transduction of noxious cold $[4,16]$. As described above, calcium is an important modulator of TRPA1 that is required for full agonist-evoked response but is also involved in channel desensitization. Notably, it was suggested that differences in calcium conditions could, in part, explain the differences reported with respect to TRPA 1 activation by cold. In recombinant systems, such an activation may occur indirectly as a result of increased $\left[\mathrm{Ca}^{++}\right] \mathrm{i}$ upon cooling as reported in both TRPA1-expressing and control HEK293 cells [54]. In contrast, noxious cooling did not evoke unspecific $\left[\mathrm{Ca}^{++}\right] \mathrm{i}$ increases in sensory neurons, maybe impairing calcium-induced activation, which could in turn explain why cold-activation of TRPA1 could not be observed in intact native cells [91]. Yet the uncertainty remains since singlechannel recordings of TRPA1 demonstrated that it could be activated by cold stimulation, even under calcium-free conditions [92]. Recent data confirmed and extended support for TRPA1-mediated cold sensitivity by showing dependence to voltage while still under calcium-free conditions [40]. Differences in the length of cold stimulation according to individual protocols might explain the discrepancies amongst the various cold studies in whole-cell patch clamp or singlechannel recordings $[6,54,93]$.
Using TRPA1 deficient mice in behavioral studies, two groups came to conflicting conclusions reporting either no differences between the KO mice and the controls [18] or a significant reduction of nociceptive behavior in the $\mathrm{KO}$ following acute noxious cold stimulation (acetone cooling and cold plate) [17]. The specific reasons for these apparent contradictions remain unknown; however, here again, methodological differences are likely to be important [77].

\section{TRPA1 and Sensory Mechanotransduction}

The role of TRPA1 as a detector of mechanical stimuli remains: controversial, yet a range of evolutionary evidence showed, for example, that a TRPA1 worm ortholog was sensitive to mechanical pressure [94]. In addition, Drosophila deficient in a specific TRPA1 homologue encoded by the painless gene $(E P(2) 2451)$ showed a decreased response to intense mechanical stimuli [95]. TRPA1 deficient mice displayed a decreased behavioral response to punctuate mechanical stimuli in the noxious range [96], although this was not observed in another study [18], and a markedly reduced firing of C-fibers following noxious mechanical stimulations [19]. In agreement, the selective TRPA1 antagonist HC030031 also significantly reduced mechanically-evoked action potential firing in rodent $\mathrm{C}$-fibers, particularly at highintensity forces [97]. With regard to the expression profile, TRPA1 is also present in epidermal keratinocytes, a part of the mechanotransduction system [19]. Collectively, the data suggests a role for TRPA1 in mechanical transduction by selective modulation of subtypes of mechanosensitive afferents.

\section{ROLE OF TRPA1 IN PAIN PATHOPHYSIOLOGY}

\section{TRPA1 as a Sensor of Tissue Damages a Key Role in No- ciceptive / Inflammatory Pain}

\section{TRPA1 Responds to a Variety of Noxious Endogenous Re- active Compounds}

In addition to being activated by exogenous physical stimuli and noxious chemicals, TRPA1 also responds to a variety of endogenous reactive compounds including ketoaldehydes, cyclopentane prostaglandins and reactive oxygen species released after tissue injury and during inflammation. These endogenous mediators act on nociceptive sensory nerve endings, thus suggesting that TRPA1 is a key sensor of tissue damage related to inflammation and oxidative stress.

In response to oxidative stress a number of reactive electrophilic ketoaldehyde are formed via lipid peroxidation. Among those, 4-oxononenal (4-ONE), derived from oxidized $\omega-6$-polyunsaturated fatty acids such as arachidonic and linoleic acid, can form stable Michael adducts with thiol containing cysteine and lysine residues of proteins. In turn 4-ONE is broken down enzymatically into other reactive metabolites such as 4-hydroxynonenal (4-HNE) [98]. In vitro 4-ONE and 4-HNE have been shown to activate recombinant or native (DRG neurons) TRPA1 channels [74, 99-102] and when injected in rodents, to induce TRPA1-dependent nocifensive behaviors as well as mechanical and cold hypersensitivity $[100,103,104]$, although some components of the responses were also shown to be TRPA1-independent. In osteoarthritis (OA) pain patients, synovial levels of 4-HNE are significantly increased $[105,106]$ and growing evidence supports a role for 4 -HNE as a pathophysiological modulator in carti- 
lage degradation [100, 101, 106, 107]. Whether 4-HNE plays a direct role in triggering pain in OA can only be speculated. Yet, the fact that TRPA1 can be detected in human synovial lining and that 4-HNE accumulates during oxidative stress to reach local concentrations $(\sim 5 \mathrm{mM})$ greatly exceeding its $\mathrm{EC}_{50}$ at TRPA1 $(\sim 50 \mu \mathrm{M})$ would support the concept [100, $108,109]$.

During inflammation, arachidonic acid is converted by cyclooxygenases into prostaglandins (PGs), which contribute to inflammatory pain and hyperalgesia through a direct action on their receptors. In addition PGs can be transformed into electrophilic compounds in vivo [110]. In particular, cyclopentenone ring-containing A- and J-series prostaglandins are formed as non-enzymatic dehydration products of PGE2 and PGD2, respectively and can be detected in humans (see [111] for a review). Among them, 15deoxy $\Delta$ prostaglandin J2 (15-dPGJ2) a PGD2 metabolite with an $\alpha, \beta$-unsaturated carbonyl moiety that can form Michael adducts has been shown to activate TRPA1 in HEK cells as well as in mouse DRGs and trigeminal neurons, an effect that was absent in TRPA1-deficient animals $[112,113]$ and that could be blocked by the TRPA1 inhibitor HC-030031 [114]. Furthermore, when injected into the skin, 15-dPGJ2 evokes acute nociceptive behaviors in rodents via a TRPA1dependent mechanism [101, 112, 113], thus indicating an additional, role of PGs in inflammatory pain via TRPA1induced nociceptor sensitization.

Nitric oxide (NO) a signaling molecule generated from arginine and oxygen by nitric oxide synthases is involved in various biological processes including vascular signaling, immune responses and neurotransmission. NO is algogenic in humans and plays an important role in pain sensitization caused by inflammation and injury in animal models [115117]. In addition to stimulating the cyclic guanosine monophosphate pathway (which in turn modulates a variety of downstream signaling targets), $\mathrm{NO}$ also forms stable adducts with cysteine residues and has been shown to activate both TRPA1 and TRPV1 in heterologous systems and in cultured primary sensory neurons [118-121]. In behavioral assays, peripheral NO-induced nociception was compromised when TRPV1 and TRPA1 were both deleted, providing genetic evidence that the peripheral nociceptive action of $\mathrm{NO}$ was mediated by both TRPV1 and TRPA1 [121].

\section{TRPA1 Expression and Function are Altered by Inflamma- tion}

TRPA1 is not only activated by endogenous proalgesic agents from the inflammatory soup, it also undergoes an inflammation-dependent modulation of its expression and function Fig (1).

In rodent DRG cells, TRPA1 (and TRPV1) mRNA levels were increased following Freund's complete adjuvant (FCA) injection into the skin [122-126], colonic injection of 2,4,6trinitrobenzenesulfonic acid (TNBS) $[124,127]$ and pancreatic inflammation induced by cerulein [128]. Likewise, TRPA1 and TRPV1 activities are potentiated by inflammation in controls, while mice containing null mutations for these channels exhibited decreased, or no inflammatory hyperalgesia $[17,18,62,123,128-130]$.

As mentioned above, $\left[\mathrm{Ca}^{++}\right] \mathrm{i}$ gating of TRPA1 channels can be strongly modulated downstream of receptor pathways that are activated by inflammatory mediators, such as neurotrophins, bradykinin, tryptase etc. [4, 18, 58, 131, 132] as well as by its own activity, resulting in an increase in nociceptor excitability. For instance, neurotrophins like nerve growth factor (NGF) and the glial cell line-derived neurotrophic factor (GDNF) family of growth factors are released in inflamed tissue where they participate to nociceptor activation and sensitization $[124,125,133,134]$. Some effects of the neurotrophins are believed to occur via alteration in expression and functional sensitivity of pain transducing receptors including not only TRPV1 or B1 [124, 135-137] but also TRPA1 [63, 123, 126, 138, 139] (however see [140]), although the ability and extent of the growth factors to potentiate TRPA1 (and TRPV1) responses seem to vary depending on the type of tissue studied (skin, muscle or colon) [125].

Bradykinin (BK) is another mediator produced in response to tissue injury, inflammation, or ischemia that activate the PLC/PKC signaling pathway, causing the release of calcium from intracellular stores. BK elicits immediate excitation of nociceptors, followed by a longer lasting sensitization to thermal and mechanical stimuli $[141,142]$. The BKevoked nociceptor excitation, thermal and mechanical hyperalgesia were strongly reduced in TRPA1-deficient mice and attenuated (mechanical hyperalgesia) by the TRPA1 antagonist AP18 [143], suggesting that TRPA1 activation mediated, or at least contributed, to the acute pain and hyperalgesia caused by BK.

Likewise, activation by tryptase and trypsin of the proteinase activated receptor-2 (PAR2), which co-expresses largely with TRPA1 in rat DRG neurons, has been shown to functionally sensitize TRPA1 in heterologous systems and DRG cells. This effect could be blocked by PLC inhibitors or mimicked by decreasing plasma membrane PIP2 levels through antibody sequestration or PLC activation, and confirmed in vivo by using the PAR2 agonist SL-NH2 at a subinflammatory dose that nonetheless led to an increase in AITC- or $\mathrm{Ca}^{++}$-evoked nocifensive behavior in rats [131].

Finally, the enhanced translocation of TRPA1 to the membrane of sensory neurons triggered by inflammation, resulting in higher amounts of functional TRPA1 channels, could be another effective mean to regulate the sensitivity of nociceptors to TRPA1 agonists and may represent one of the mechanisms controlling TRPA1 function in response to acute activation and inflammatory signals [140].

\section{Blocking TRPA1 is Analgesic or Antihyperalgesic in Skin, Joint and Visceral Models of Inflammatory Pain}

In addition to small molecule TRPA1 antagonists such as HC-030031, AP-18 and A-967079, which all emerged from drug discovery efforts, endogenous inhibitors of TRP channels have recently been identified. Resolvins, such as resolvin D1, D2 (RvD1, RvD2) and E1 (RvE1), are lipid mediators biosynthesized during the resolution phase of acute inflammation from $\omega-3$ polyunsaturated fatty acids. They display potent pro-resolving and anti-inflammatory actions (see review in [144]) and have also proven to be very potent inhibitors of the TRPA1 (RvD1, RvD2) and TRPV1 (RvE1, RvD2) channels [145, 146].

The ability of TRPA1 blockade by small molecules antagonists, antisense oligonucleotides and resolvins to reduce signs of hypersensitivity has been explored in various rodent 
models of inflammatory pain using several endpoints. For instance, the mechanical hypersensitivity induced by intraplantar injection of FCA, Carrageenan or the major proinflammatory cytokine TNF $\alpha$ as well as by intra-articular injection of FCA was reduced by systemic administration of HC-030031 and A-967079 at plasma exposures believed to engage TRPA1 [147, 148] or upon local injection of AP-18, RvD1 or RvD2 [143, 145, 146, 149], an effect that was abolished in TRPA1-deficient mice [143, 145]. However, TRPA1 antisense administration did not reduce mechanical hypersensitivity even though it had an effect on cold allodynia [123]. In a model of osteoarthritis induced by intraarticular injection of monosodium iodoacetate (MIA) the results were inconsistent: A-967079 was reported to reverse the MIA-induced reduction in grip force [148] whereas HC030031 failed to reverse the shift in weight bearing or to block place-preference elicited by intra-articular lidocaine (used as a measure of ongoing pain) [148, 150] although both compounds were used at doses shown to reduce AITCinduced nocifensive behaviors.

Systemic HC-030031, locally administered AP18, or transient knock-down of TRPA1 reduced FCA-induced cold hyperalgesia in rats $[104,123,143,151]$ without affecting acute noxious cold sensation. Heat hyperalgesia on the other hand was neither affected by AP18 nor by TRPA1 antisense administration $[143,145,151]$. The positive effect on this symptom observed after RvD1 or RvD2 administration may be attributed to inhibition by the resolvins of thermo-TRPs like TRPV3 and TRPV1 [145, 146, 152].

Interestingly, although both wild-type and TRPA1deficient mice developed mechanical hyperalgesia 24 hours after FCA injection, only the wild-type mice displayed a sustained mechanical hyperalgesia for 3 weeks following FCA [143, 149]. Thus, endogenous activation of peripheral TRPA1 appears to play a key role in the long lasting mechanical hyperalgesia observed after intra-articular injection of FCA; while, in the early stage of the inflammatory insult, compensatory mechanisms in TRPA1-deficient mice would mask the TRPA1 requirement [143]. In agreement, the nociceptive and hyperalgesic responses measured within 24 hours after induction of inflammation were reduced, but not abolished, by TRPA1 antagonists [104, 123, 147, 149, 151]; but see [143]. Similarly, TNF $\alpha$-induced hyperalgesia was reduced but not suppressed in TRPA1-deficient mice, suggesting that other mechanisms than just TRPA1 activation contributed in the early AITC-, FCA- or TNF $\alpha$-induced nociceptive responses [149].

Finally, in a mice model of pancreatitis caused by repeated injection of cerulein, HC-030031 and the TRPV1 antagonist AMG 9810 could synergistically reverse the change in exploratory behavior (believed to reflect pancreatitis-induced discomfort and pain), suggesting that reagents targeting both channels could be worthwhile exploring in acute pancreatitis pain [128].

Although some inconsistencies exist (likely affected by differences in methodologies), several lines of evidence support a critical role for endogenous activation of peripheral TRPA1 in the development of mechanical and cold hyperalgesia following tissue injury and inflammation. TRPA1 is up-regulated during inflammation, directly activated and indirectly sensitized by endogenous inflammatory mediators.
Thus, blocking of TRPA1 activity appears to be a relevant mechanistic approach to decrease mechanical hyperalgesia, a key symptom that contributes to movement-evoked pain in patients suffering from chronic nociceptive or inflammatory pain. Another major complaint from notably OA patients is pain at rest, which presumably depends on sustained activity in nociceptive fibers. The reduction in spontaneous firing of spinal wide-dynamic range neurons (WDR) to intra-articular administration of FCA and in exploratory behavior in a model of pancreatic pain points towards a role for TRPA1 in ongoing pain during overt inflammation [128, 153]. In contrast, when inflammation dissipates like in the chronic phase of MIA-induced arthritis, TRPA1 antagonists did not inhibit the spontaneous firing of spinal neurons or a measure of ongoing pain $[150,153]$ indicating that they might not be very effective on pain at rest in less inflammatory conditions like advanced OA.

In summary, inhibiting peripheral activation/sensitization of nociceptor afferent endings by blocking TRPA1 channels appears to be an attractive approach to relieve some of the symptoms in patients suffering from acute or chronic nociceptive inflammatory pain conditions, including arthritic pain.

\section{Role of TRPA1 in Neuropathic Pain}

While the role of TRPA1 in inflammatory pain is supported by a wealth of concurring evidence, its contribution to the pathophysiology of neuropathic pain is more debatable.

\section{Alteration in TRPA1 Expression and Function after Nerve Injury}

In animals, the changes in TRPA1 expression profile were variable depending on the specific model of nerve injury studied. For instance, after chronic constriction injury of the sciatic nerve (CCI), TRPA1 mRNA levels in rat DRG neurons were reported to be slightly but significantly increased at day 7 post-surgery [154] or left unchanged from day 2 to 28 (R. Grant, AstraZeneca R\&D, unpublished data)". In mice, the expression was instead significantly reduced in DRGs at day 7 and 14, in agreement with a reduction in the number of AITC-sensitive cells [62]. In the rat spared nerve injury (SNI) model, the TRPA1 gene was down-regulated at 4 and 15 days post-surgery and returned to normal or above normal at 3 months [155]. In the mouse partial nerve injury model (Seltzer method), TRPA1 mRNA levels were strongly reduced in L4 and L5 DRGs at times where mechanical allodynia could be observed [155]. A reduction in TRPA1 level was also observed 7 days after complete sciatic nerve transection [155]. In the spinal nerve ligation (SNL) model, Noguchi's group reported an increase in TRPA1 mRNA expression in the uninjured trkA-expressing small-to-medium L4 DRG neurons 1-14 days after L5 spinal nerve ligation, aligned with the development and maintenance of cold hyperalgesia in the hind paw [123, 156]. Immunohistochemical studies confirmed TRPA1 up-regulation in the L4 DRG and trafficking of the channels in small diameter myelinated and unmyelinated peripheral terminals. In agreement, the percentages of AITC-sensitive L4 DRG cells and of peripheral $\mathrm{A} \delta$-fibers were increased in SNL compared to sham and naive rats, suggesting that following nerve injury TRPA 1 is up-regulated on intact $A \delta$-fibers, then contributing to cold hypersensitivity [157]. In contrast, TRPA1 
expression was decreased in the injured L5 DRG cells in rats and in five inbred mice strains [158]. Overall, it appeared as if TRPA1 is down-regulated in injured neurons and upregulated in neighboring uninjured neurons, the net effects being more obviously detected after complete sciatic nerve transection or in the SNL model. Indeed in the SNL model, all neurons from the L5 DRG are injured and all those from the L4 are spared, whereas in CCI, the injured neurons distribute to several ganglia. Upregulation of TRPA1 has also recently been reported in the streptozotocin-induced model of diabetic neuropathy in rats at a time points where cold hyperalgesia was observed [159].

In human, expression of TRPA1 was increased in smallto medium-sized DRG neurons obtained from patients having undergone brachial plexus repair following avulsion injury [63]. However, investigating the potential correlation between TRPA1 expression and the presence or absence of neuropathic pain symptoms, Morgan et al. [64] showed no significant difference between levels of TRPA1 in lingual neuromas from patients with or without symptoms of dysaesthesia, and no relationship either between TRPA1 expression and VAS scores for pain, tingling or discomfort. Furthermore, despite a net decrease of TRPA1 mRNA levels observed in some nerve injury models, animals still displayed neuropathic-like signs of hypersensitivity. Therefore, it cannot be concluded that neuropathic pain symptoms in rodent or human are unequivocally linked to changes in TRPA1 channel expression.

Sensitization of the TRPA1 channel could also contribute to the development of neuropathic pain symptoms following nerve injury as it does during inflammation. For instance, in the rat SNL model, NGF is synthesized and released in the L5 degenerative nerve fibers and acts upon nearby sensory fibers, potentially inducing TRPA1 up-regulation in the intact L4 DRG, thus increasing cold hyperalgesia [123]. In agreement, the magnitude of the response to AITC of L4 DRG cells and $A \delta$-fibers in the periphery is significantly larger in SNL compared with sham and naive rats [157]. Also, in a mice model of chemotherapy-induced neuropathic pain, repeated administration of paclitaxel has been shown to activate PAR2 and the downstream enzymes PLC, PKCe, and PKA, resulting in the sensitization of TRPA1 along with TRPV1 and TRPV4. In turn, blocking downstream signaling pathways of PAR2 or the TRP channels attenuated paclitaxel-induced mechanical, heat, or cold hypersensitivity [160].

\section{Blocking of TRPA1 Reverses Hypersensitivity in Rodent Models of Neuropathic Pain}

The potential role of TRPA1 activation in the pathogenesis of neuropathic pain has also been addressed in rodents using pharmacological tools and antisense knock down. For instance, cold hypersensitivity was reduced by HC-030031 in the SNI model as well as in paclitaxel- or oxaliplatininduced neuropathy models $[104,148,159,161,162]$, by A967079 in the CCI model $[104,148,159,161,162]$ and following intrathecal administration of TRPA1 antisense in the rat SNL model [123, 156]. Importantly, HC-030031 and A967079 had no effect on noxious cold sensation in naive animals, suggesting distinct roles of TRPA1 in physiological and pathological states $[104,148,159,161,162]$. Similarly, mechanical hyperalgesia observed following SNL, repeated paclitaxel or acute oxaliplatin administration, or in diabetic rats was reduced by HC-030031 or a close analogue [147, 161-163]. In agreement, oxaliplatin-induced mechanical and cold allodynia were absent and cisplatin-evoked mechanical allodynia was reduced in TRPA1-deficient mice [104, 148, $159,161,162]$. Paclitaxel-induced heat hyperalgesia was also reduced by HC-030031 [160].

Collectively, the data suggest that TRPA1 antagonism is a potential approach to treating symptoms of neuropathic pain. However, inconsistencies exist and the strength of evidence is so far weaker than for inflammatory pain.

\section{Human Data Supporting TRPA1 Role in Pathological Pain}

Recently, a human heritable pain syndrome has been linked to a gain-of function mutation in the TRPA1 channel. Familial Episodic Pain Syndrome is characterized by episodes of debilitating upper body pain, triggered by fasting and physical stress although baseline sensory thresholds were normal. Enhanced secondary hyperalgesia to punctate stimuli on treatment with AITC was observed. The mutated channels show a 5-fold increase in inward current on activation at normal resting potentials and, like the wild type channel, can be activated by $\mathrm{Ca}^{++}$, cinnamaldehyde, 4-HNE and cold and blocked by HC-030031 [164].

\section{Emerging Role of Spinal TRPA1 Channels in Pain Pathophysiology}

The main lines of evidence supporting the role of TRPA1 in pain pathophysiology are based on its expression on peripheral nerve fibers. However, recent findings indicate that presynaptic activation of TRPA1 channels expressed on central terminals of primary afferents enhances glutamate release and facilitates excitatory transmission in the substantia gelatinosa between primary afferents and projection neurons [165], contributing as a result to inflammation- or nerve injury-induced hypersensitivity. The effects of intrathecal administration of RvD1, RvD2, A-967079 or an analogue of HC-030031 on mechanical hypersensitivity in various inflammatory or neuropathic pain models [146, 163, 166, 167] as well as on spontaneous excitatory post synaptic currents and C-fiber-evoked long-term potentiation in the spinal cord [146] suggest an additional beneficial site of action in spinal cord for CNS penetrant TRPA1 antagonists. On the other hand, a recent report attributes the antinociceptive activity of acetaminophen to the agonistic properties of two of its metabolites on TRPA1 channels in the spinal cord and proposes spinal TRPA1 activation as a potential pharmacological strategy to alleviate pain [168]. Further studies are warranted to understand this apparent discrepancy.

\section{A ROLE FOR TRPA1 IN SENSITIZATION OF VA- GAL SENSORY NEURONS INNERVATING THE AIR- WAYS}

Asthma is a chronic condition of airways inflammation. It is caused by a combination of genetic and environmental factors including exposure to irritants and allergens that will trigger uncontrolled inflammatory reactions and dramatic sensitization of the airways sensory neurons. Common treatments involve beta- 2 adrenergic agonists and corticosteroids, generally given in combination so as to maximize efficacy and limit the risks associated with standalone beta-2 
adrenergics or corticosteroid treatments [169, 170]. Beta-2 adrenergics contribute to smooth muscle relaxation, vasodilation and subsequent dilation of the airways whereas corticosteroid drugs bind to intracellular receptors signaling to response elements that will either up- or down-regulate inflammation-induced gene expression (up-regulation of annexin A1; down-regulation of TNF $\alpha$; GM-CSF; chemo- and interleukins) [171].

Due to its expression in vagal sensory neurons innervating the airways and gating by inflammatory mediators and the ability of agonist to evoke coughing in animal and human, TRPA1 has been proposed as the target of pro-tussive agents. Thus TRPA1 blockers may find application in the treatment of allergic airway inflammation, asthma and COPD [172-175]. For instance, in models of acute asthma, the typical allergen-induced responses like leukocyte extravasation, mucus production, cytokines and chemokines levels that led to airways hyperreactivity were all significantly lowered in TRPA1-, but not in TRPV1-deficient mice. A similar phenotype in rodents was also observed following pharmacological blockade using HC-030031 [176].

\section{POTENTIAL ROLE OF TRPA1 IN ITCH}

Itch or pruritus is defined as an unpleasant sensation that elicits the desire or reflex to scratch. As such, itch serves a protective role by warning against harmful agents in the environment. However, when it accompanies conditions such as chronic skin and systemic disorders, atopic dermatis, psoriasis, renal- or liver failures, peripheral neuropathy etc. itch becomes chronic causing debilitating sensory experiences with many similarities to pain. Complex interactions exist between pain and itch, both sensations sharing at least in part the same neural pathways, peripheral mediators, pathophysiological mechanisms, central processing and even treatments (see [177] for a review). Histamine is a well-known pruritogen which is mainly released by skin mast cells in response to external stimuli. Histamine-dependent itch in humans can be effectively blocked by histamine receptor antagonists and involves activation of TRPV1. Chronic itch, by contrast, is insensitive to antihistamine treatment and represents a significant unmet medical need. Recent findings have demonstrated that TRPA1, but not TRPV1, is a downstream transduction channel of histamine-independent chronic itch [178]. Oxidative stress also induces profound scratching behaviors, which are largely histamine- and TRPV1-independent, but TRPA1-dependent. Antioxidants and TRPA1 antagonists have shown efficacy in itch models in mice and may potentially be used to treat oxidative stress induced itch conditions in human too [179]. The recent demonstration by Liu et al. that oxidant-induced scratching behaviors were prevented in mice treated with the TRPA1 antagonist HC030031 or in TRPA1 deficient animals seems to support this hypothesis.

\section{TRPA1 POLYMODAL ACTIVITY AND IN VITRO AS- SAY DESIGNS FOR DRUG DISCOVERY}

Several groups have been involved in exploring drug discovery and development projects targeted at TRPA1. In the majority of cases, the primary indications are various types of pain and respiratory disorders (COPD and asthma) [180]. Here we summarize results from various in vitro assays, mostly fluorescence-based and electrophysiology, which were used in screening and mode of action studies. For ease of reference to readers interested in assay designs, these parts are separated by assay type including references to the structural determinants underlying the mode of action whenever possible.

\section{Fluorescence-based Assays}

A straightforward and common way to characterize compounds activity is by using $\mathrm{Ca}^{++}$imaging on multiwellplate readers like the FLIPR ${ }^{\mathrm{TM}}$ or Hamamatsu ${ }^{\mathrm{TM}}$ instruments. In addition to calcium imaging, assay designers at RedPoint Bio Corporation used hTRPA1 recombinant cells to set up assays based on a fluorescent membrane potential probe [and used these] to characterize direct thymol activation of hTRPA1 and its blockade by camphor [181]. From its structure, thymol is not expected to behave as an electrophile in physiological conditions and may not exhibit the typical traits of covalent binding activators. At low micromolar concentration, thymol is a pure agonist, whereas at higher concentration it started to act as a functional antagonist, maybe only inducing rapid channel desensitization [44]. Indeed, a feature of some typical TRPA1 activators like AITC is that they tend to cause rapid desensitization of the channel, especially in presence of physiological concentrations of calcium this can make the activators functionally behave as antagonists [182, 183]. In fluorescence screens, where the time resolution is limited, agonist-induced desensitization is a serious issue as it is often difficult to distinguish at first pass an antagonist from an agonist causing rapid desensitization. The timeframe during which a given reference agonist (like AITC) will induce continued activation of the channel is a critical parameter in the design of reliable screening assays. Recently, using fluorescence screening, a team from Pfizer identified a new activator compound that did not covalently bind TRPA1 through cysteine binding, and that proved to be a potent and selective activator of both rat and human TRPA1 in vitro (PF-4840154) [184]. Out of a panel of 100 targets, this new tool only showed micromolar activity on dopamine D3 receptor, noradrenaline transporter and sigma opioid receptor. Although PF-4840154 significantly blocked hERG channel ( IC $_{50} 580 \mathrm{nM}$ ), it was inactive at hTRPV1, hTRPV4, hTRPM8, and other established pain targets. These characteristics make it a superior alternative for setting up in vitro assays on mice and human TRPA1. Notably, upon intraplantar injection PF-4840154 induced potent nocifensive behaviors in wild-type mice but not in their knock-out counterparts, behaviors that were fully reversed by pre-treatment with the TRPA1 antagonist HC-030031.

Independent of the mechanism involving $\mathrm{N}$-terminal cysteine binding, zinc is a pulmonary irritant that can directly activate TRPA 1 . Its mechanism of action involved ion influx through the TRPA1 channel followed by interaction with an intracellular C-terminal site (C983, H1021) [185-187]. Using FLIPR calcium fluorescence on HEK293 hTRPA1, an $\mathrm{EC}_{50}$ of $2.3 \mu \mathrm{M}$ was reported for stable $\mathrm{Zn}$ activation in intact cells. In addition to zinc, other heavy metals like cadmium and copper were also shown to activate TRPA1 directly and caused C-fibers sensitization in pulmonary airways; these effects were essentially absent from knock-out mice, yet their specific potencies were not reported for recombinant in vitro TRPA1 systems [188]. The 
agonist properties of heavy metal ions like zinc make them another class of activators potentially useful for in vitro assay designs.

A recent report described in details a HEK293 hTRPA1 calcium fluorescence assay based on Fluo-4 AM probe and the FlexStation $3^{\mathrm{TM}}$ reader. The authors used a non-steroidal anti-inflammatory drug as reference agonist, flufenamic acid (FFA), to activate the channel $\left(\mathrm{EC}_{50}=55.4 \mu \mathrm{M}\right)$ [189]. FFA has been reported as a non-electrophilic and non-covalent ligand for TRPA1, TRPM8, TRPV1 and TRPV3. They suggested that that it has potential as a structural starting point for the development of a new class of reversible, nonreactive and non-volatile TRPA1 ligands. Regardless of the background cell line, WI-38 or inducible HEK, the potency of FFA appeared consistent when determined by calcium fluorescence on the human isoforms $\left(\mathrm{EC}_{50}=24-57 \mu \mathrm{M}\right)$. Its potency inhuman isoforms was within a 3 -fold range of that of the rat isoform expressed in oocytes (where FFA seemed to show very limited voltage dependency of TRPA1 current activation $\left(\mathrm{EC}_{50}=78 \mu \mathrm{M}\right.$ at $-100 \mathrm{mV}$ to $148 \mu \mathrm{M}$ at $\left.+100 \mathrm{mV}\right)$ [190].

\section{Electrophysiology Profiling Assays}

Transfected Xenopus laevis oocytes are a common transient expression system used in electrophysiological studies of ion channels. The large size of the oocytes (about $1.0 \mathrm{~mm}$ ) eases cell handling and the robust protein synthesis machinery of the tetraploid organism usually results in efficient surface expression of the channel of interest. Oocytes based assays using temperature ramps were used to characterize the basis of heat/ cold sensitivity across various species and their dependence on ARD across species. Oocyte recordings on TRPA1 from rat, snakes, humans and their chimeras led to the characterization of two functionally different modules along the ARD that are responsible for the differential thermosensation across species (see above) [24].

With regard to automated electrophysiology, Sophion and Scottish Biomedical have reported a detailed protocol for stable recording of TRPA1 currents using proprietary HEK293 recombinant cells kept at $-60 \mathrm{mV}$ and a voltage ramp ranging from $-100 \mathrm{mV}$ to $+50 \mathrm{mV}$ in a $400 \mathrm{~ms}$ pulse. The use of nominally calcium free solutions and supercinnamaldehyde as a reference agonist seem to slow or stabilize channel desensitization, and warranted stable outward current recording after a short interval where the current needed to reach steady state levels [191].

In the context of drug discovery projects, it will be important to identify if endogenous TRPA 1 activators have any potential to trigger pore dilation like that observed with AITC (see above) or cause leftward shift in the apparition of TRPA1 outward $\mathrm{K}+$ current to some physiologically relevant depolarized potentials. If so, it will be worthwhile testing whether the large pore antagonist properties of reference compounds like ruthenium red and HC-030031 are also shared by future TRPA1 drug candidates. Additionally, it will be important to assess if these are efficient in blocking the inward current (typically detected in $\mathrm{Ca}^{++}$fluorescence) and the outward current at depolarized potential in high $\mathrm{Ca}^{++}$ conditions (typical voltage ramp assay).

\section{Targeting the Temperature Sensitivity of TRPA1 with in vitro Assays}

In mammals, TRPA1 orthologs are primarily known as chemosensors and eventual cold detectors [31, 91]. Yet, TRPA1 evolved into distinct temperature sensors across the animal kingdom, and discrete structural features may underlie most of species specificities with respect to heat and cold detection [192]. In particular, mammals and fish TRPA1 typically do not respond to heat, whereas snake, mosquitoes and drosophila's channel exhibit differential heat-sensitivity thresholds [193-195]. At the extreme end of subtle heat detection is TRPA1 from Crotalus atrox, which is able to sense infrared radiations while it seemed to show no sensitivity to cold [196].

Since the discovery that human or rat TRPA1 opened at temperatures below $17{ }^{\circ} \mathrm{C}$, assay designers have developed cold sensing assays to screen and study the mode of action for compounds that modulate this activity [31, 92]. A versatile temperature-dependent assay was reported that relied on the rapid TaqMan temperature control to trigger thermoTRPs activation; results were shown to reliably translate to native rat dorsal root ganglia neurons in either 384 or 96 well formats [197].

\section{TRPA1 IN THE NEWS}

\section{Recent Advances Towards Clinical Concept Testing for Pain And Respiratory Disorders}

Glenmark Pharmaceuticals Ltd is developing GRC17536 an orally available TRPA1 receptor antagonist for the treatment of neuropathic pain and respiratory disorders (Table 2, Fig. (3). In February 2012, Glenmark announced that GRC-17536 had successfully completed a Phase I trial (single ascending dose and multiple ascending dose) with the drug being well tolerated up to the maximum dose tested. A good pharmacokinetic profile was reported, seemingly devoid of gender or age effects. In March 2012, the company disclosed plans to initiate a 4-week randomized, doubleblind, parallel-group, placebo-controlled, proof-of-concept Phase II trial in 55 patients with painful diabetic neuropathy to assess the efficacy, safety and tolerability of GRC-17536. A Phase I/IIa trial in healthy adult volunteers and mild asthma patients using an inhaled version of GRC-17536 is reportedly expected to start in Jun 2012. The study will also include response to an allergen test [198, 199]. In January 2012, Cubist Pharmaceuticals and Hydra Biosciences have filed for regulatory approval to initiate human clinical studies with their small molecule TRPA1 antagonist CB-189,625 in development for the treatment of acute pain and certain inflammatory conditions Fig. (3), Table 2. The open-label dose-escalation Phase I study to assess the safety and pharmacokinetics of CB-189, 625 in healthy volunteers was expected to start in the first quarter of 2012 [200].

In conclusion, TRPA1 has emerged as an attractive molecular target for the development of novel inflammatory and possibly neuropathic pain therapies. In addition, TRPA1 antagonists may also hold promise as treatments for certain respiratory diseases and itch conditions. Various lines of evidence support the therapeutic utility of TRPA1 antagonists including (1) expression in relevant neuronal population, (2) demonstration that the channel is activated and 
Table 2. Properties of Representative TPA1 Antagonists Compounds in Preclinical Exploration

\begin{tabular}{|c|c|c|c|c|}
\hline Compound & ID and/or sponsor & $\mathrm{EC}_{50}(\mu \mathrm{M})$ & Properties & Ref. \\
\hline$\$ 07$ & HC-030031, Hydra & h: $6.2^{a}$ & $\begin{array}{l}\text { Reversed formalin-induced behaviors in mouse at } 300 \mathrm{mg} / \mathrm{kg} \text { i.p. } \\
\text { to levels comparable to gabapentin. }\end{array}$ & [78] \\
\hline$\$ 08$ & Glenmark & h: $0.05-0.10^{a}$ & $\begin{array}{l}\text { Reversed AITC-induced } \\
\text { flinches in rat by } 72 \% \text { at } 3 \mathrm{mg} / \mathrm{kg} \text { p.o. }\end{array}$ & {$[202]$} \\
\hline$\$ 09$ & Univ. Ferrara & h: $0.40^{b}$ & & {$[203]$} \\
\hline$\$ 10$ & $\begin{array}{l}\text { A-967079, } \\
\text { Abbott }\end{array}$ & $\begin{array}{l}\mathrm{h}: 0.067^{a} ; \mathrm{r}: \\
0.29^{a}\end{array}$ & $\begin{array}{l}\text { Rat bioavailability }=37 \% \text { at } 2 \mathrm{mg} / \mathrm{kg} \text {, reaching } 0.72 \mu \mathrm{Mol} / \mathrm{L} \text { in } \\
\text { plasma at } 30 \mathrm{~min} \text { with half-life of } 0.81 \mathrm{~h} \text {. The compound is brain } \\
\text { penetrant with brain/plasma ratio of } 0.75 .1000 \text {-selective vs other } \\
\text { TRP channels. Reverses AITC-induced nocifensive responses and } \\
\text { osteoarthritic pain in rat } \mathrm{ED}_{50} 23 \mathrm{mg} / \mathrm{kg} \text {, p.o. }\end{array}$ & {$[204]$} \\
\hline$\$ 11$ & $\mathrm{~J} \& \mathrm{~J}$ & $\begin{array}{l}\text { h: } 0.13^{c} \\
\text { r: } 0.02^{d}\end{array}$ & & {$[205]$} \\
\hline$\$ 12$ & Univ. Rome & $\mathrm{h}: 2.8^{e}$ & & {$[206]$} \\
\hline
\end{tabular}

$\mathrm{h}=$ human; $\mathrm{r}=$ rat; agonists used in EC50 studies: ${ }^{\mathrm{a}}$ AITC, ${ }^{\mathrm{b}}$ acrolein, ${ }^{\mathrm{c}} \$ 02,{ }^{\mathrm{d}} \mathrm{BITC},{ }^{\mathrm{e}}$ allyl isothiocyanate.<smiles>CC(C)c1ccc(NC(=O)Cn2cnc3c2c(=O)n(C)c(=O)n3C)cc1</smiles>

\$07, HC030031<smiles>CCC(=N\O)/C(C)=C/c1ccc(F)cc1</smiles>

\$10, A-967079<smiles>Cn1c(=O)c2c(ncn2CC(=O)Nc2nc(-c3ccc(Cl)cc3)cs2)n(C)c1=O</smiles>

$\$ 08$<smiles>COc1cccc(C2NC(=S)NC3=C2C(=O)c2ccccc23)c1</smiles>

$\$ 11$<smiles>Cn1c(=O)c2c(ccn2CC(=O)Nc2ccc(C(F)(F)F)cc2)n(C)c1=O</smiles>

$\$ 09$<smiles>CC(C)(CC(O)CC(=O)CCc1ccc2c(c1)OCO2)c1ccccc1</smiles>

$\$ 12$

Fig. (3). Structures of TRPA1 agonists in Table 2.

modulated by multiple inflammatory mediators and their downstream pathways, (3) its selective activation causes pain in human and nocifensive reactions in animal, and conversely its inhibition reverse signs of inflammatory and neuropathic pain symptoms in animals and (4) its genetic linkage to a painful disease state in man.

Certainly, the chemical properties of existing compounds and the observed species specifity, conditioning compound progression and the choice of the surrogate species, are challenging factors for TRPA1 drug discovery. Therefore, the outcomes of forthcoming clinical proof of concept studies will be instrumental in furthering our understanding of the clinical value of this potential new class of analgesic or antiinflammatory drugs.

\section{CONFLICT OF INTEREST}

The authors confirm that this article content has no conflicts of interest.

\section{ACKNOWLEDGEMENT}

Declared none.

\section{REFERENCES}

[1] Landsteiner K, Di Somma AA. Studies on the sensitization of animals with simple chemical compounds : v. sensitization to diazomethane and mustard oil. J Exp Med 1938; 68(4): 505-12.

[2] Koltzenburg M, McMahon SB. Plasma extravasation in the rat urinary bladder following mechanical, electrical and chemical stimuli: evidence for a new population of chemosensitive primary sensory afferents. Neurosci Lett 1986; 72(3): 352-6.

[3] Reeh PW, Kocher L, Jung S. Does neurogenic inflammation alter the sensitivity of unmyelinated nociceptors in the rat? Brain Res 1986; 384(1): 42-50.

[4] Jordt SE, Bautista DM, Chuang HH, et al. Mustard oils and cannabinoids excite sensory nerve fibres through the TRP channel ANKTM1. Nature 2004; 427(6971): 260-5.

[5] Jaquemar D, Schenker T, Trueb B. An ankyrin-like protein with transmembrane domains is specifically lost after oncogenic transformation of human fibroblasts. J Biol Chem 1999; 274(11): 7325-33.

[6] Latorre R, Zaelzer C, Brauchi S. Structure-functional intimacies of transient receptor potential channels. Q Rev Biophys 2009; 42(3): 201-46.

[7] Montell C. The TRP superfamily of cation channels. Sci STKE 2005; 2005(272): re3.

[8] Clapham DE. SnapShot: mammalian TRP channels. Cell 2007; 129(1): 220 . 
[9] Clapham DE, Runnels LW, Strübing C. The TRP ion channel family. Nat Rev Neurosci 2001; 2(6): 387-96.

[10] Clapham DE, Montell C, Schultz G, et al. International Union of Pharmacology. XLIII. Compendium of voltage-gated ion channels: transient receptor potential channels. Pharmacol Rev 2003; 55(4): 591-6.

[11] Macpherson LJ, Geierstanger $\mathrm{BH}$, Viswanath $\mathrm{V}$, et al. The pungency of garlic: activation of TRPA1 and TRPV1 in response to allicin. Curr Biol 2005; 15(10): 929-34.

[12] Sidi S, Friedrich RW, Nicolson T. NompC TRP channel required for vertebrate sensory hair cell mechanotransduction. Science 2003; 301(5629): 96-9.

[13] Walker RG, Willingham AT, Zuker CS. A Drosophila mechanosensory transduction channel. Science 2000; 287(5461): 2229-34.

[14] Li W, Feng Z, Sternberg PW, Xu XZ. A C. elegans stretch receptor neuron revealed by a mechanosensitive TRP channel homologue. Nature 2006; 440(7084): 684-7.

[15] Göpfert MC, Albert JT, Nadrowski B, Kamikouchi A. Specification of auditory sensitivity by Drosophila TRP channels. Nat Neurosci 2006; 9(8): 999-1000.

[16] Nagata K, Duggan A, Kumar G, García-Añoveros J. Nociceptor and hair cell transducer properties of TRPA1, a channel for pain and hearing. J Neurosci 2005; 25(16): 4052-61.

[17] Kwan KY, Allchorne AJ, Vollrath MA, et al. TRPA1 contributes to cold, mechanical, and chemical nociception but is not essential for hair-cell transduction. Neuron 2006; 50(2): 277-89.

[18] Bautista DM, Jordt SE, Nikai T, et al. TRPA1 mediates the inflammatory actions of environmental irritants and proalgesic agents. Cell 2006; 124(6): 1269-82.

[19] Kwan KY, Glazer JM, Corey DP, Rice FL, Stucky CL. TRPA1 modulates mechanotransduction in cutaneous sensory neurons. J Neurosci 2009; 29(15): 4808-19.

[20] Cvetkov TL, Huynh KW, Cohen MR, Moiseenkova-Bell VY. Molecular architecture and subunit organization of TRPA1 ion channel revealed by electron microscopy. J Biol Chem 2011; 286(44): 38168-76.

[21] Cvetkov TL, Huynh KW, Cohen MR, Moiseenkova-Bell VY. Nanospring behaviour of ankyrin repeats. Nature 2006; 440(7081): 246-9.

[22] Sotomayor M, Corey DP, Schulten K. In search of the hair-cell gating spring elastic properties of ankyrin and cadherin repeats. Structure 2005; 13(4): 669-82.

[23] Nilius B, Prenen J, Owsianik G. Irritating channels: the case of TRPA1. J Physiol 2011; 589(Pt 7): 1543-9.

[24] Cordero-Morales JF, Gracheva EO, Julius D. Cytoplasmic ankyrin repeats of transient receptor potential A1 (TRPA1) dictate sensitivity to thermal and chemical stimuli. Proc Natl Acad Sci USA 2011; 108(46): E1184-91.

[25] Sura L, Zíma V, Marsakova L, Hynkova A, Barvík I, Vlachova V. C-terminal acidic cluster is involved in the $\mathrm{Ca} 2+$-induced regulation of the human TRPA1 channel. J Biol Chem 2012; 287(22):18067-77.

[26] Samad A, Sura L, Benedikt J, et al. The C-terminal basic residues contribute to the chemical- and voltage-dependent activation of TRPA1. Biochem J 2011; 433(1): 197-204.

[27] Schmidt M, Dubin AE, Petrus MJ, Earley TJ, Patapoutian A. Nociceptive signals induce trafficking of TRPA1 to the plasma membrane. Neuron 2009; 64(4): 498-509.

[28] Berg KAP, Patwardhan MA, Akopian AN. Receptor and channel heteromers as pain targets. Pharmaceuticals 2012; 5: 29.

[29] Salas MM, Hargreaves KM, Akopian AN. TRPA1-mediated responses in trigeminal sensory neurons: interaction between TRPA1 and TRPV1. Eur J Neurosci 2009; 29(8): 1568-78.

[30] Patil M, Patwardhan A, Salas MM, Hargreaves KM, Akopian AN. Cannabinoid receptor antagonists AM251 and AM630 activate TRPA1 in sensory neurons. Neuropharmacology 2011; 61(4): 77888.

[31] Story GM, Peier AM, Reeve AJ, et al. ANKTM1, a TRP-like channel expressed in nociceptive neurons, is activated by cold temperatures. Cell 2003; 112(6): 819-29.

[32] Staruschenko A, Jeske NA, Akopian AN. Contribution of TRPV1TRPA1 interaction to the single channel properties of the TRPA1 channel. J Biol Chem 2010; 285(20): 15167-77.

[33] Akopian AN, Ruparel NB, Jeske NA, Hargreaves KM. Transient receptor potential TRPA1 channel desensitization in sensory neurons is agonist dependent and regulated by TRPV1-directed internalization. J Physiol 2007; 583(Pt 1): 175-93.

[34] Akopian AN, Ruparel NB, Patwardhan A, Hargreaves KM. Cannabinoids desensitize capsaicin and mustard oil responses in sensory neurons via TRPA1 activation. J Neurosci 2008; 28(5): 1064-75.

[35] Kobayashi K, Fukuoka T, Obata K, et al. Distinct expression of TRPM8, TRPA1, and TRPV1 mRNAs in rat primary afferent neurons with adelta/c-fibers and colocalization with trk receptors. J Comp Neurol 2005; 493(4): 596-606.

[36] Klionsky L, Tamir R, Gao B, et al. Species-specific pharmacology of Trichloro(sulfanyl)ethyl benzamides as transient receptor potential ankyrin 1 (TRPA1) antagonists. Mol Pain 2007; 3: 39.

[37] Chen J, Kym PR. TRPA1: the species difference. J Gen Physiol 2009; 133(6): 623-5.

[38] Chen J, Zhang XF, Kort ME, et al. Molecular determinants of species-specific activation or blockade of TRPA1 channels. J Neurosci 2008; 28(19): 5063-71.

[39] Nagatomo K, Kubo Y. Caffeine activates mouse TRPA1 channels but suppresses human TRPA1 channels. Proc Natl Acad Sci USA 2008; 105(45): 17373-8.

[40] Karashima Y, Talavera K, Everaerts W, et al. TRPA1 acts as a cold sensor in vitro and in vivo. Proc Natl Acad Sci USA 2009; 106(4): 1273-8.

[41] Bianchi BR, Zhang XF, Reilly RM, Kym PR, Yao BB, Chen J. Species comparison and pharmacological characterization of human, monkey, rat, and mouse TRPA1 channels. J Pharmacol Exp Ther 2012; 341(2): 360-8.

[42] Nagatomo K, Ishii H, Yamamoto T, Nakajo K, Kubo Y. The Met268Pro mutation of mouse TRPA1 changes the effect of caffeine from activation to suppression. Biophys J 2010; 99(11): 3609-18.

[43] Xiao B, Dubin AE, Bursulaya B, Viswanath V, Jegla TJ, Patapoutian A. Identification of transmembrane domain 5 as a critical molecular determinant of menthol sensitivity in mammalian TRPA1 channels. J Neurosci 2008; 28(39): 9640-51.

[44] Karashima Y, Damann N, Prenen J, et al. Bimodal action of menthol on the transient receptor potential channel TRPA1. J Neurosci 2007; 27(37): 9874-84.

[45] Karashima Y, Prenen J, Meseguer V, Owsianik G, Voets T, Nilius B. Modulation of the transient receptor potential channel TRPA1 by phosphatidylinositol 4,5-biphosphate manipulators. Pflugers Arch 2008; 457(1): 77-89.

[46] Bobkov YV, Corey EA, Ache BW. The pore properties of human nociceptor channel TRPA1 evaluated in single channel recordings. Biochim Biophys Acta 2011; 1808(4): 1120-8.

[47] Doerner JF, Gisselmann G, Hatt H, Wetzel CH. Transient receptor potential channel A1 is directly gated by calcium ions. J Biol Chem 2007; 282(18): 13180-9.

[48] Kim D, Cavanaugh EJ. Requirement of a soluble intracellular factor for activation of transient receptor potential A1 by pungent chemicals: role of inorganic polyphosphates. J Neurosci 2007; 27(24): 6500-9.

[49] Karashima Y, Prenen J, Talavera K, Janssens A, Voets T, Nilius B. Agonist-induced changes in $\mathrm{Ca}(2+)$ permeation through the nociceptor cation channel TRPA1. Biophys J 2010; 98(5): 773-83.

[50] Chen J, Kim D, Bianchi BR, et al. Pore dilation occurs in TRPA1 but not in TRPM8 channels. Mol Pain 2009; 5: 3.

[51] Puopolo MB, Binshtok AM, Woolf CJ, Bean BP, Yao GL. Permeation of the lidocaine derivative QX-314 in TRPV1 and TRPA1 channels: Is pore dilation required? Meeting of the Society for Neuroscience; San Diego CA, 2010.

[52] Banke TG, Chaplan SR, Wickenden AD. Dynamic changes in the TRPA1 selectivity filter lead to progressive but reversible pore dilation. Am J Physiol Cell Physiol 2010; 298(6): C1457-68.

[53] Banke TG. The dilated TRPA1 channel pore state is blocked by amiloride and analogues. Brain Res 2011; 1381: 21-30.

[54] Zurborg S, Yurgionas B, Jira JA, Caspani O, Heppenstall PA. Direct activation of the ion channel TRPA1 by Ca2+. Nat Neurosci 2007; 10(3): 277-9.

[55] Lu SG, Gold MS. Inflammation-induced increase in evoked calcium transients in subpopulations of rat dorsal root ganglion neurons. Neuroscience 2008; 153(1): 279-88.

[56] Ozaki Y, Kitamura N, Tsutsumi A, Dayanithi G, Shibuya I. NGFinduced hyperexcitability causes spontaneous fluctuations of 
intracellular $\mathrm{Ca} 2+$ in rat nociceptive dorsal root ganglion neurons. Cell Calcium 2009; 45(3): 209-15.

[57] Wang YY, Chang RB, Waters HN, McKemy DD, Liman ER. The nociceptor ion channel TRPA1 is potentiated and inactivated by permeating calcium ions. J Biol Chem 2008; 283(47): 32691-703.

[58] Bandell M, Story GM, Hwang SW, et al. Noxious cold ion channel TRPA1 is activated by pungent compounds and bradykinin. Neuron 2004; 41(6): 849-57.

[59] Bautista DM, Sigal YM, Milstein AD, et al. Pungent agents from Szechuan peppers excite sensory neurons by inhibiting two-pore potassium channels. Nat Neurosci 2008; 11(7): 772-9.

[60] Patil MJ, Jeske NA, Akopian AN. Transient receptor potential V1 regulates activation and modulation of transient receptor potential A1 by Ca2+. Neuroscience 2010; 171(4): 1109-19.

[61] Bautista DM, Movahed P, Hinman A, et al. Pungent products from garlic activate the sensory ion channel TRPA1. Proc Natl Acad Sci USA 2005 ; 102(34): 12248-52.

[62] Caspani O, Zurborg S, Labuz D, Heppenstall PA. The contribution of TRPM8 and TRPA1 channels to cold allodynia and neuropathic pain. PLoS ONE 2009; 4(10): e7383.

[63] Anand U, Otto WR, Facer P, et al. TRPA1 receptor localisation in the human peripheral nervous system and functional studies in cultured human and rat sensory neurons. Neurosci Lett 2008; 438(2): 221-7.

[64] Morgan CR, Bird EV, Robinson PP, Boissonade FM. TRPA1 expression in human lingual nerve neuromas in patients with and without symptoms of dysaesthesia. Neurosci Lett 2009; 465(2): 189-93.

[65] Nassenstein C, Kwong K, Taylor-Clark T, et al. Expression and function of the ion channel TRPA1 in vagal afferent nerves innervating mouse lungs. J Physiol 2008; 586(6): 1595-604.

[66] Andrade EL, Luiz AP, Ferreira J, Calixto JB. Pronociceptive response elicited by TRPA1 receptor activation in mice. Neuroscience 2008; 152(2): 511-20.

[67] Streng T, Axelsson HE, Hedlund P, et al. Distribution and function of the hydrogen sulfide-sensitive TRPA1 ion channel in rat urinary bladder. Eur Urol 2008; 53(2): 391-9.

[68] Gratzke C, Streng T, Waldkirch E, et al. Transient receptor potential A1 (TRPA1) activity in the human urethra--evidence for a functional role for TRPA1 in the outflow region. Eur Urol 2009; 55(3): 696-704.

[69] Corey DP, García-Añoveros J, Holt JR, et al. TRPA1 is a candidate for the mechanosensitive transduction channel of vertebrate hair cells. Nature 2004; 432(7018): 723-30.

[70] Earley S, Gonzales AL, Crnich R. Endothelium-dependent cerebral artery dilation mediated by TRPA1 and $\mathrm{Ca} 2+$-Activated $\mathrm{K}+$ channels. Circ Res 2009; 104(8): 987-94.

[71] Bodkin JV, Brain SD. Transient receptor potential ankyrin 1: emerging pharmacology and indications for cardiovascular biology. Acta Physiol (Oxf) 2011; 203(1): 87-98.

[72] Talavera K, Gees M, Karashima Y, et al. Nicotine activates the chemosensory cation channel TRPA1. Nat Neurosci 2009; 12(10): 1293-9.

[73] Hinman A, Chuang HH, Bautista DM, Julius D. TRP channel activation by reversible covalent modification. Proc Natl Acad Sci USA 2006; 103(51): 19564-8

[74] Macpherson LJ, Dubin AE, Evans MJ, et al. Noxious compounds activate TRPA1 ion channels through covalent modification of cysteines. Nature 2007; 445(7127): 541-5.

[75] Wang L, Cvetkov TL, Chance MR, Moiseenkova-Bell VY. Identification of in vivo disulfide conformation of TRPA1 ion channel. J Biol Chem 2012; 287(9): 6169-76.

[76] Berge OG. Predictive validity of behavioural animal models for chronic pain. Br J Pharmacol 2011; 164(4): 1195-206.

[77] Stucky CL, Dubin AE, Jeske NA, Malin SA, McKemy DD, Story GM. Roles of transient receptor potential channels in pain. Brain Res Rev 2009; 60(1): 2-23.

[78] McNamara CR, Mandel-Brehm J, Bautista DM, et al. TRPA1 mediates formalin-induced pain. Proc Natl Acad Sci USA 2007; 104(33): 13525-30.

[79] Handwerker HO, Forster C, Kirchhoff C. Discharge patterns of human $\mathrm{C}$-fibers induced by itching and burning stimuli. J Neurophysiol 1991; 66(1): 307-15.

[80] Koltzenburg M, Handwerker HO, Torebjörk HE. The ability of humans to localise noxious stimuli. Neurosci Lett 1993; 150(2): $219-22$.
[81] Koltzenburg M, Lundberg LE, Torebjörk HE. Dynamic and static components of mechanical hyperalgesia in human hairy skin. Pain 1992; 51(2): 207-19.

[82] Schmelz M, Schmidt R, Ringkamp M, Handwerker HO, Torebjörk HE. Sensitization of insensitive branches of $\mathrm{C}$ nociceptors in human skin. J Physiol 1994; 480 ( Pt 2): 389-94.

[83] Baraldi PG, Preti D, Materazzi S, Geppetti P. Transient receptor potential ankyrin 1 (TRPA1) channel as emerging target for novel analgesics and anti-inflammatory agents. J Med Chem 2010; 53(14): 5085-107.

[84] Ohta T, Imagawa T, Ito S. Novel agonistic action of mustard oil on recombinant and endogenous porcine transient receptor potential V1 (pTRPV1) channels. Biochem Pharmacol 2007; 73(10): 164656.

[85] Prescott J, Swain-Campbell N. Responses to repeated oral irritation by capsaicin, cinnamaldehyde and ethanol in PROP tasters and non-tasters. Chem Senses 2000; 25(3): 239-46.

[86] Macpherson LJ, Hwang SW, Miyamoto T, Dubin AE, Patapoutian A, Story GM. More than cool: promiscuous relationships of menthol and other sensory compounds. Mol Cell Neurosci 2006; 32(4): 335-43.

[87] Brône B, Peeters PJ, Marrannes R, et al. Tear gasses CN, CR, and CS are potent activators of the human TRPA1 receptor. Toxicol Appl Pharmacol 2008; 231(2): 150-6.

[88] Bessac BF, Sivula M, von Hehn CA, Caceres AI, Escalera J, Jordt SE. Transient receptor potential ankyrin 1 antagonists block the noxious effects of toxic industrial isocyanates and tear gases. FASEB J 2009; 23(4): 1102-14.

[89] Ballantyne B, Swanston DW. The irritant potential of dilute solutions of ortho-chlorobenzylidene malon onitrile (CS) on the eye and tongue. Acta Pharmacol Toxicol (Copenh) 1973; 32(3): 26677.

[90] Babes A, Zorzon D, Reid G. Two populations of cold-sensitive neurons in rat dorsal root ganglia and their modulation by nerve growth factor. Eur J Neurosci 2004; 20(9): 2276-82.

[91] Caspani O, Heppenstall PA. TRPA1 and cold transduction: an unresolved issue? J Gen Physiol 2009; 133(3): 245-9.

[92] Sawada Y, Hosokawa H, Hori A, et al. Cold sensitivity of recombinant TRPA1 channels. Brain Res 2007; 1160: 39-46.

[93] Nagata K. TRP channels as target sites for insecticides: physiology, pharmacology and toxicology. Invert Neurosci 2007; 7(1): 31-7.

[94] Kindt KS, Viswanath V, Macpherson L, et al. Caenorhabditis elegans TRPA-1 functions in mechanosensation. Nat Neurosci 2007; 10(5): 568-77.

[95] Tracey WD Jr, Wilson RI, Laurent G, Benzer S. painless, a Drosophila gene essential for nociception. Cell 2003; 113(2): 26173.

[96] Kwan KY, Corey DP. Burning cold: involvement of TRPA1 in noxious cold sensation. J Gen Physiol 2009; 133(3): 251-6.

[97] Kerstein PC, del Camino D, Moran MM, Stucky CL. Pharmacological blockade of TRPA1 inhibits mechanical firing in nociceptors. Mol Pain 2009; 5: 19.

[98] Kuiper HC, Miranda CL, Sowell JD, Stevens JF. Mercapturic acid conjugates of 4-hydroxy-2-nonenal and 4-oxo-2-nonenal metabolites are in vivo markers of oxidative stress. J Biol Chem 2008; 283(25): 17131-8.

[99] Macpherson LJ, Xiao B, Kwan KY, et al. An ion channel essential for sensing chemical damage. J Neurosci 2007; 27(42): 11412-5.

[100] Trevisani M, Siemens J, Materazzi S, et al. 4-Hydroxynonenal, an endogenous aldehyde, causes pain and neurogenic inflammation through activation of the irritant receptor TRPA1. Proc Natl Acad Sci USA 2007; 104(33): 13519-24.

[101] Andersson DA, Gentry C, Moss S, Bevan S. Transient receptor potential A1 is a sensory receptor for multiple products of oxidative stress. J Neurosci 2008; 28(10): 2485-94.

[102] Taylor-Clark TE, Undem BJ, Macglashan DW Jr, Ghatta S, Carr MJ, McAlexander MA. Prostaglandin-induced activation of nociceptive neurons via direct interaction with transient receptor potential A1 (TRPA1). Mol Pharmacol 2008; 73(2): 274-81.

[103] Graepel R, Fernandes ES, Aubdool AA, Andersson DA, Bevan S, Brain SD. 4-oxo-2-nonenal (4-ONE): evidence of transient receptor potential ankyrin 1-dependent and -independent nociceptive and vasoactive responses in vivo. J Pharmacol Exp Ther 2011; 337(1): $117-24$.

[104] del Camino D, Murphy S, Heiry M, et al. TRPA1 contributes to cold hypersensitivity. J Neurosci 2010; 30(45): 15165-74. 
[105] Grigolo B, Roseti L, Fiorini M, Facchini A. Enhanced lipid peroxidation in synoviocytes from patients with osteoarthritis. J Rheumatol 2003; 30(2): 345-7.

[106] Morquette B, Shi Q, Lavigne P, Ranger P, Fernandes JC, Benderdour M. Production of lipid peroxidation products in osteoarthritic tissues: new evidence linking 4-hydroxynonenal to cartilage degradation. Arthritis Rheum 2006; 54(1): 271-81.

[107] Patapoutian A, Tate S, Woolf CJ. Transient receptor potential channels: targeting pain at the source. Nat Rev Drug Discov 2009; 8(1): 55-68.

[108] Kochukov MY, McNearney TA, Fu Y, Westlund KN. Thermosensitive TRP ion channels mediate cytosolic calcium response in human synoviocytes. Am J Physiol Cell Physiol 2006; 291(3): C424-32.

[109] Esterbauer H, Schaur RJ, Zollner H. Chemistry and biochemistry of 4-hydroxynonenal, malonaldehyde and related aldehydes. Free Radic Biol Med 1991; 11(1): 81-128.

[110] Stamatakis K, Pérez-Sala D. Prostanoids with cyclopentenone structure as tools for the characterization of electrophilic lipidprotein interactomes. Ann N Y Acad Sci 2006; 1091: 548-70.

[111] Milne GL, Yin H, Morrow JD. Human biochemistry of the isoprostane pathway. J Biol Chem 2008; 283(23): 15533-7

[112] Cruz-Orengo L, Dhaka A, Heuermann RJ, et al. Cutaneous nociception evoked by 15 -delta PGJ2 via activation of ion channel TRPA1. Mol Pain 2008; 4: 30.

[113] Materazzi S, Nassini R, Andrè E, et al. Cox-dependent fatty acid metabolites cause pain through activation of the irritant receptor TRPA1. Proc Natl Acad Sci USA 2008; 105(33): 12045-50.

[114] Taylor-Clark TE, McAlexander MA, Nassenstein C, et al. Relative contributions of TRPA1 and TRPV1 channels in the activation of vagal bronchopulmonary $\mathrm{C}$-fibres by the endogenous autacoid 4oxononenal. J Physiol 2008; 586(14): 3447-59.

[115] Lowenstein CJ, Dinerman JL, Snyder SH. Nitric oxide: a physiologic messenger. Ann Intern Med 1994; 120(3): 227-37.

[116] Meller ST, Gebhart GF. Nitric oxide (NO) and nociceptive processing in the spinal cord. Pain 1993; 52(2): 127-36.

[117] Zochodne DW, Levy D. Nitric oxide in damage, disease and repair of the peripheral nervous system. Cell Mol Biol (Noisy-le-grand) 2005; 51(3): 255-67.

[118] Yoshida T, Inoue R, Morii T, et al. Nitric oxide activates TRP channels by cysteine S-nitrosylation. Nat Chem Biol 2006; 2(11): 596-607.

[119] Sawada Y, Hosokawa H, Matsumura K, Kobayashi S. Activation of transient receptor potential ankyrin 1 by hydrogen peroxide. Eur J Neurosci 2008; 27(5): 1131-42.

[120] Takahashi N, Mizuno Y, Kozai D, et al. Molecular characterization of TRPA1 channel activation by cysteine-reactive inflammatory mediators. Channels (Austin) 2008; 2(4): 287-98.

[121] Miyamoto T, Dubin AE, Petrus MJ, Patapoutian A. TRPV1 and TRPA1 mediate peripheral nitric oxide-induced nociception in mice. PLoS ONE 2009; 4(10): e7596.

[122] Amaya F, Shimosato G, Nagano M, et al. NGF and GDNF differentially regulate TRPV1 expression that contributes to development of inflammatory thermal hyperalgesia. Eur J Neurosci 2004; 20(9): 2303-10.

[123] Obata K, Katsura H, Mizushima T, et al. TRPA1 induced in sensory neurons contributes to cold hyperalgesia after inflammation and nerve injury. J Clin Invest 2005; 115(9): 2393401.

[124] Malin SA, Molliver DC, Koerber HR, et al. Glial cell line-derived neurotrophic factor family members sensitize nociceptors in vitro and produce thermal hyperalgesia in vivo. J Neurosci 2006; 26(33): 8588-99.

[125] Malin S, Molliver D, Christianson JA, et al. TRPV1 and TRPA1 function and modulation are target tissue dependent. J Neurosci 2011; 31(29): 10516-28.

[126] Diogenes A, Akopian AN, Hargreaves KM. NGF up-regulates TRPA1: implications for orofacial pain. J Dent Res 2007; 86(6): 550-5.

[127] Yang J, Li Y, Zuo X, Zhen Y, Yu Y, Gao L. Transient receptor potential ankyrin-1 participates in visceral hyperalgesia following experimental colitis. Neurosci Lett 2008; 440(3): 237-41.

[128] Schwartz ES, Christianson JA, Chen X, et al. Synergistic role of TRPV1 and TRPA1 in pancreatic pain and inflammation. Gastroenterology 2011; 140(4): 1283-91.
[129] Caterina MJ, Leffler A, Malmberg AB, et al. Impaired nociception and pain sensation in mice lacking the capsaicin receptor. Science 2000; 288(5464): 306-13.

[130] Mitrovic M, Shahbazian A, Bock E, Pabst MA, Holzer P. Chemonociceptive signalling from the colon is enhanced by mild colitis and blocked by inhibition of transient receptor potential ankyrin 1 channels. Br J Pharmacol 2010; 160(6): 1430-42.

[131] Dai Y, Wang S, Tominaga M, et al. Sensitization of TRPA1 by PAR2 contributes to the sensation of inflammatory pain. J Clin Invest 2007; 117(7): 1979-87.

[132] Wang S, Dai Y, Fukuoka T, et al. Phospholipase C and protein kinase A mediate bradykinin sensitization of TRPA1: a molecular mechanism of inflammatory pain. Brain 2008; 131(Pt 5): 1241-51.

[133] Lewin GR, Rueff A, Mendell LM. Peripheral and central mechanisms of NGF-induced hyperalgesia. Eur J Neurosci 1994; 6(12): 1903-12.

[134] Woolf CJ, Safieh-Garabedian B, Ma QP, Crilly P, Winter J. Nerve growth factor contributes to the generation of inflammatory sensory hypersensitivity. Neuroscience 1994; 62(2): 327-31.

[135] Shu X, Mendell LM. Nerve growth factor acutely sensitizes the response of adult rat sensory neurons to capsaicin. Neurosci Lett 1999; 274(3): 159-62.

[136] Bron R, Klesse LJ, Shah K, Parada LF, Winter J. Activation of Ras is necessary and sufficient for upregulation of vanilloid receptor type 1 in sensory neurons by neurotrophic factors. Mol Cell Neurosci 2003; 22(1): 118-32.

[137] Vellani V, Zachrisson O, McNaughton PA. Functional bradykinin B1 receptors are expressed in nociceptive neurones and are upregulated by the neurotrophin GDNF. J Physiol 2004; 560(Pt 2): 391-401.

[138] Elitt CM, McIlwrath SL, Lawson JJ, et al. Artemin overexpression in skin enhances expression of TRPV1 and TRPA1 in cutaneous sensory neurons and leads to behavioral sensitivity to heat and cold. J Neurosci 2006; 26(33): 8578-87.

[139] Ciobanu C, Reid G, Babes A. Acute and chronic effects of neurotrophic factors BDNF and GDNF on re[sponses mediated by thermo-sensitive TRP channels in cultured rat dorsal root ganglion neurons. Brain Res 2009; 1284: 54-67.

[140] Yoshida N, Kobayashi K, Yu L, et al. Inhibition of TRPA1 channel activity in sensory neurons by the glial cell line-derived neurotrophic factor family member, artemin. Mol Pain 2011; 7: 41.

[141] Dray A, Perkins M. Bradykinin and inflammatory pain. Trends Neurosci 1993; 16(3): 99-104.

[142] Mizumura K, Sugiura T, Katanosaka K, Banik RK, Kozaki Y. Excitation and sensitization of nociceptors by bradykinin: what do we know? Exp Brain Res 2009; 196(1): 53-65.

[143] Petrus M, Peier AM, Bandell M, et al. A role of TRPA1 in mechanical hyperalgesia is revealed by pharmacological inhibition. Mol Pain 2007; 3: 40.

[144] Ji RR, Xu ZZ, Strichartz G, Serhan CN. Emerging roles of resolvins in the resolution of inflammation and pain. Trends Neurosci 2011; 34(11): 599-609.

[145] Bang S, Yoo S, Yang TJ, Cho H, Kim YG, Hwang SW. Resolvin D1 attenuates activation of sensory transient receptor potential channels leading to multiple anti-nociception. Br J Pharmacol 2010; 161(3): 707-20.

[146] Park CK, Xu ZZ, Liu T, Lü N, Serhan CN, Ji RR. Resolvin D2 is a potent endogenous inhibitor for transient receptor potential subtype V1/A1, inflammatory pain, and spinal cord synaptic plasticity in mice: distinct roles of resolvin D1, D2, and E1. J Neurosci 2011; 31(50): 18433-8.

[147] Eid SR, Crown ED, Moore EL, et al. HC-030031, a TRPA1 selective antagonist, attenuates inflammatory- and neuropathyinduced mechanical hypersensitivity. Mol Pain 2008; 4: 48.

[148] Chen J, Joshi SK, DiDomenico S, et al. Selective blockade of TRPA1 channel attenuates pathological pain without altering noxious cold sensation or body temperature regulation. Pain 2011; 152(5): 1165-72.

[149] Fernandes ES, Russell FA, Spina D, et al. A distinct role for transient receptor potential ankyrin 1 , in addition to transient receptor potential vanilloid 1, in tumor necrosis factor alphainduced inflammatory hyperalgesia and Freund's complete adjuvant-induced monarthritis. Arthritis Rheum 2011; 63(3): 81929.

[150] Okun A, Liu P, Davis P, et al. Afferent drive elicits ongoing pain in a model of advanced osteoarthritis. Pain 2012; 153(4): 924-33. 
[151] da Costa DS, Meotti FC, Andrade EL, Leal PC, Motta EM, Calixto JB. The involvement of the transient receptor potential A1 (TRPA1) in the maintenance of mechanical and cold hyperalgesia in persistent inflammation. Pain 2010; 148(3): 431-7.

[152] Xu ZZ, Zhang L, Liu T, et al. Resolvins RvE1 and RvD1 attenuate inflammatory pain via central and peripheral actions. Nat Med 2010; 16(5): 592-7.

[153] McGaraughty S, Chu KL, Perner RJ, Didomenico S, Kort ME, Kym PR. TRPA1 modulation of spontaneous and mechanically evoked firing of spinal neurons in uninjured, osteoarthritic, and inflamed rats. Mol Pain 2010; 6: 14 .

[154] Frederick J, Buck ME, Matson DJ, Cortright DN. Increased TRPA1, TRPM8, and TRPV2 expression in dorsal root ganglia by nerve injury. Biochem Biophys Res Commun 2007; 358(4): 105864.

[155] Staaf S, Oerther S, Lucas G, Mattsson JP, Ernfors P. Differential regulation of TRP channels in a rat model of neuropathic pain. Pain 2009; 144(1-2): 187-99.

[156] Katsura H, Obata K, Mizushima T, et al. Antisense knock down of TRPA1, but not TRPM8, alleviates cold hyperalgesia after spinal nerve ligation in rats. Exp Neurol 2006; 200(1): 112-23.

[157] Ji G, Zhou S, Carlton SM. Intact Adelta-fibers up-regulate transient receptor potential A1 and contribute to cold hypersensitivity in neuropathic rats. Neuroscience 2008; 154(3): 1054-66.

[158] Persson AK, Xu XJ, Wiesenfeld-Hallin Z, Devor M, Fried K. Expression of DRG candidate pain molecules after nerve injury--a comparative study among five inbred mouse strains with contrasting pain phenotypes. J Peripher Nerv Syst 2010; 15(1): 2639.

[159] Barrière DA, Rieusset $\mathrm{J}$, Chanteranne $\mathrm{D}$, et al. Paclitaxel therapy potentiates cold hyperalgesia in streptozotocin-induced diabetic rats through enhanced mitochondrial reactive oxygen species production and TRPA1 sensitization. Pain 2012; 153(3): 553-61.

[160] Chen Y, Yang C, Wang ZJ. Proteinase-activated receptor 2 sensitizes transient receptor potential vanilloid 1 , transient receptor potential vanilloid 4 , and transient receptor potential ankyrin 1 in paclitaxel-induced neuropathic pain. Neuroscience 2011; 193: 44051.

[161] Materazzi S, Fusi C, Benemei S, et al. TRPA1 and TRPV4 mediate paclitaxel-induced peripheral neuropathy in mice via a glutathionesensitive mechanism. Pflugers Arch 2012; 463(4): 561-9.

[162] Nassini R, Gees M, Harrison S, et al. Oxaliplatin elicits mechanical and cold allodynia in rodents via TRPA1 receptor stimulation. Pain 2011; 152(7): 1621-31.

[163] Wei H, Hämäläinen MM, Saarnilehto $M$, et al. Attenuation of mechanical hypersensitivity by an antagonist of the TRPA1 ion channel in diabetic animals. Anesthesiology 2009; 111(1): 147-54.

[164] Kremeyer B, Lopera F, Cox JJ, et al. A gain-of-function mutation in TRPA1 causes familial episodic pain syndrome. Neuron 2010; 66(5): 671-80.

[165] Kosugi M, Nakatsuka T, Fujita T, et al. Activation of TRPA1 channel facilitates excitatory synaptic transmission in substantia gelatinosa neurons of the adult rat spinal cord. J Neurosci 2007; 27(16): 4443-51.

[166] Huang J, Zhang X, McNaughton PA. Modulation of temperaturesensitive TRP channels. Semin Cell Dev Biol 2006; 17(6): 638-45.

[167] Wei H, Koivisto A, Saarnilehto M, et al. Spinal transient receptor potential ankyrin 1 channel contributes to central pain hypersensitivity in various pathophysiological conditions in the rat. Pain 2011; 152(3): 582-91.

[168] Andersson DA, Gentry C, Alenmyr L, et al. TRPA1 mediates spinal antinociception induced by acetaminophen and the cannabinoid Delta(9)-tetrahydrocannabiorcol. Nat Commun 2011; 2: 551

[169] Au DH, Udris EM, Curtis JR, et al. Association between chronic heart failure and inhaled beta-2-adrenoceptor agonists. Am Heart J 2004; 148(5): 915-20.

[170] Barnes PJ, Adcock IM. Glucocorticoid resistance in inflammatory diseases. Lancet 2009; 373(9678): 1905-17.

[171] Newton R. Molecular mechanisms of glucocorticoid action: what is important? Thorax 2000; 55(7): 603-13.

[172] Stokes A, Wakano C, Koblan-Huberson M, Adra CN, Fleig A, Turner H. TRPA1 is a substrate for de-ubiquitination by the tumor suppressor CYLD. Cell Signal 2006; 18(10): 1584-94.
[173] Andrè E, Gatti R, Trevisani M, et al. Transient receptor potential ankyrin receptor 1 is a novel target for pro-tussive agents. $\mathrm{Br} \mathrm{J}$ Pharmacol 2009; 158(6): 1621-8.

[174] Banner KH, Igney F, Poll C. TRP channels: emerging targets for respiratory disease. Pharmacol Ther 2011; 130(3): 371-84.

[175] Birrell MA, Belvisi MG, Grace M, et al. TRPA1 agonists evoke coughing in guinea pig and human volunteers. Am J Respir Crit Care Med 2009; 180(11): 1042-7.

[176] Caceres AI, Brackmann M, Elia MD, et al. A sensory neuronal ion channel essential for airway inflammation and hyperreactivity in asthma. Proc Natl Acad Sci USA 2009; 106(22): 9099-104.

[177] Ikoma A, Steinhoff M, Ständer S, Yosipovitch G, Schmelz M. The neurobiology of itch. Nat Rev Neurosci 2006; 7(7): 535-47.

[178] Wilson SR, Gerhold KA, Bifolck-Fisher A, et al. TRPA1 is required for histamine-independent, Mas-related $\mathrm{G}$ protein-coupled receptor-mediated itch. Nat Neurosci 2011; 14(5): 595-602.

[179] Liu T, Ji RR. Oxidative stress induces itch via activation of transient receptor potential subtype ankyrin 1 in mice. Neurosci Bull 2012; 28(2): 145-54.

[180] Reuters T. Thomson Integrity data on TRPA1. Available at: https://integrity.thomson-pharma.com [Accessed: 2012 March].

[181] Lee SP, Buber MT, Yang Q, et al. Thymol and related alkyl phenols activate the hTRPA1 channel. Br J Pharmacol 2008; 153(8): 1739-49

[182] Penuelas A, Tashima K, Tsuchiya S, et al. Contractile effect of TRPA1 receptor agonists in the isolated mouse intestine. Eur $\mathrm{J}$ Pharmacol 2007; 576(1-3): 143-50.

[183] Leamy AW, Shukla P, McAlexander MA, Carr MJ, Ghatta S. Curcumin ((E,E)-1,7-bis(4-hydroxy-3-methoxyphenyl)-1,6-heptadiene-3,5-dione) activates and desensitizes the nociceptor ion channel TRPA1. Neurosci Lett 2011; 503(3): 157-62.

[184] Ryckmans T, Aubdool AA, Bodkin JV, et al. Design and pharmacological evaluation of PF-4840154, a non-electrophilic reference agonist of the TrpA1 channel. Bioorg Med Chem Lett 2011; 21(16): 4857-9.

[185] Hu H, Bandell M, Petrus MJ, Zhu MX, Patapoutian A. Zinc activates damage-sensing TRPA1 ion channels. Nat Chem Biol 2009; 5(3): 183-90.

[186] Banke TG, Wickenden AD. Wickenden, Intracellular zinc irritates TRPA1. Nat Chem Biol 2009; 5(3): 141-2.

[187] Andersson DA, Gentry C, Moss S, Bevan S. Clioquinol and pyrithione activate TRPA1 by increasing intracellular Zn2+. Proc Natl Acad Sci USA 2009; 106(20): 8374-9.

[188] Gu Q, Lin RL. Heavy metals zinc, cadmium, and copper stimulate pulmonary sensory neurons via direct activation of TRPA1. J Appl Physiol 2010; 108(4): 891-7.

[189] Luo J, Zhu Y, Zhu MX, Hu H. Cell-based calcium assay for medium to high throughput screening of TRP channel functions using FlexStation 3. J Vis Exp 2011; (54). pii: 3149.

[190] Hu H, Tian J, Zhu Y, et al. Activation of TRPA1 channels by fenamate nonsteroidal anti-inflammatory drugs. Pflugers Arch 2010; 459(4): 579-92.

[191] Sophion Q. Patch HTX Application note. Available at: http://www.soph-ion.dk/downloads/ligand-gated-ion-channels/trpchannels.aspx [Accessed: 2012 March].

[192] Geng J, Liang D, Jiang K, Zhang P. Molecular evolution of the infrared sensory gene TRPA1 in snakes and implications for functional studies. PLoS ONE 2011; 6(12): e28644.

[193] Hamada FN, Rosenzweig M, Kang K, et al. An internal thermal sensor controlling temperature preference in Drosophila. Nature 2008; 454(7201): 217-20.

[194] Prober DA, Zimmerman S, Myers BR, et al. Zebrafish TRPA1 channels are required for chemosensation but not for thermosensation or mechanosensory hair cell function. J Neurosci 2008; 28(40): 10102-10.

[195] Wang G, Qiu YT, Lu T, et al. Anopheles gambiae TRPA1 is a heat-activated channel expressed in thermosensitive sensilla of female antennae. Eur J Neurosci 2009; 30(6): 967-74.

[196] Gracheva EO, Ingolia NT, Kelly YM, et al. Molecular basis of infrared detection by snakes. Nature 2010; 464(7291): 1006-11.

[197] Aneiros E, Dabrowski M. Novel temperature activation cell-based assay on thermo-TRP ion channels. J Biomol Screen 2009; 14(6) 662-7.

[198] clinicaltrial.gov [Home page on the internet] Clinical Trials, Available at: http://clinicaltrials.gov/ct2/show/NCT01556152 [Accessed: $17^{\text {th }} 2012$ March]. 
[199] Glenmark. [Home page on the internet] Glenmark press communicate. frm http://www.gle-nmarkpharma.com/GLN NWS/PDF/Glenmark_GRC_17536_Phase_I_completion.pdf [Āccessed: 2012 March].

[200] Bioscience H. Hydra Bioscience press communicate. Available at: http://www.hydrabiosciences.com/p-df/press_release/2012_01_10.pdf. [Accessed March 2012].

[201] Gijsen HJ, Berthelot D, Zaja M, Brône B, Geuens I, Mercken M. Analogues of morphanthridine and the tear gas dibenz[b,f]$[1,4]$ oxazepine (CR) as extremely potent activators of the human transient receptor potential ankyrin 1 (TRPA1) channel. J Med Chem 2010; 53 (19): 7011-20.

[202] Muthuppalniappan MTA, Kumar S, Margal S, et al. Preparation of quinazolinedione derivatives as TRPA1 modulators. US patent 20090325987, 2009.
[203] Baraldi PG, Romagnoli R, Saponaro G, et al. 7-Substitutedpyrrolo[3,2-d]pyrimidine-2,4-dione derivatives as antagonists of the transient receptor potential ankyrin 1 (TRPA1) channel: a promising approach for treating pain and inflammation. Bioorg Med Chem 2012; 20(5): 1690-8.

[204] Perner RJK, Didomenico S, Jr, Chen J, Vasudevan A. Heteroarylalkenone oxime derivatives as TRPA1 antagonists useful in the treatment of various diseases. WO 2009089083, 2009.

[205] Gijsen HJ, Berthelot D, De Cleyn MA, Geuens I, Brône B, Mercken M. Tricyclic 3,4-dihydropyrimidine-2-thione derivatives as potent TRPA1 antagonists. Bioorg Med Chem Lett 2012; 22(2): 797-800.

[206] Morera E, De Petrocellis L, Morera L, et al. Synthesis and biological evaluation of [6]-gingerol analogues as transient receptor potential channel TRPV1 and TRPA1 modulators. Bioorg Med Chem Lett 2012; 22(4): 1674-7.

Received: August 09, 2012

Revised: August 09, 2012

Accepted: August 16, 2012

(C) Radresa et al.; Licensee Bentham Open.

This is an open access article licensed under the terms of the Creative Commons Attribution Non-Commercial License (http://creativecommons.org/licenses/by-nc/3.0/) which permits unrestricted, non-commercial use, distribution and reproduction in any medium, provided the work is properly cited. 